BNL-113668-2017-JA

\title{
Chain Length Dependence of Energies of Electron and Triplet Polarons in Oligofluorenes
}

\author{
Hung Cheng Chen, Paiboon Sreearunothai, \\ Andrew R. Cook, Sadayuki Asaoka, Qin Wu, John R. Miller
}

Submitted to J. Phys. Chem. C

March 2017

Chemistry Department

Brookhaven National Laboratory

\author{
U.S. Department of Energy \\ USDOE Office of Science (SC), \\ Basic Energy Sciences (BES) (SC-22)
}

Notice: This manuscript has been authored by employees of Brookhaven Science Associates, LLC under Contract No. DE- SC0012704 with the U.S. Department of Energy. The publisher by accepting the manuscript for publication acknowledges that the United States Government retains a non-exclusive, paid-up, irrevocable, world-wide license to publish or reproduce the published form of this manuscript, or allow others to do so, for United States Government purposes. 


\section{DISCLAIMER}

This report was prepared as an account of work sponsored by an agency of the United States Government. Neither the United States Government nor any agency thereof, nor any of their employees, nor any of their contractors, subcontractors, or their employees, makes any warranty, express or implied, or assumes any legal liability or responsibility for the accuracy, completeness, or any third party's use or the results of such use of any information, apparatus, product, or process disclosed, or represents that its use would not infringe privately owned rights. Reference herein to any specific commercial product, process, or service by trade name, trademark, manufacturer, or otherwise, does not necessarily constitute or imply its endorsement, recommendation, or favoring by the United States Government or any agency thereof or its contractors or subcontractors. The views and opinions of authors expressed herein do not necessarily state or reflect those of the United States Government or any agency thereof. 


\title{
Chain Length Dependence of Energies of Electron
}

\section{and Triplet Polarons in Oligofluorenes}

Hung Cheng Chen ${ }^{\dagger}$, Paiboon Sreearunothai ${ }^{\ddagger}$, Andrew R. Cook ${ }^{\dagger}$, Sadayuki Asaoka ${ }^{\perp}$, Qin Wu $^{\S}$, John R. Miller ${ }^{*}+$

${ }^{\dagger}$ Chemistry Department and ${ }^{\S}$ Center of Functional Nanomaterials, Brookhaven National Laboratory, Upton, NY 11973

${ }^{\ddagger}$ Sirindhorn International Institute of Technology, Thammasat University - Pathum Thani 12121, Thailand

${ }^{\perp}$ Faculty of Materials Science and Engineering, Kyoto Institute of Technology, Matsugasaki, Sakyo-ku, Kyoto 606-8585, Japan

Correspondence: jrmiller@bnl.gov

\begin{abstract}
Bimolecular equilibria measured the one-electron reduction potentials and triplet free energies $\left(\Delta \mathrm{G}_{\mathrm{T}}^{\circ}\right)$ of oligo(9,9-dihexyl)fluorenes and a polymer with lengths of $n=1-10$ and 57 repeat units. Accurate oneelectron potentials can be measured electrochemically only for the shorter oligomers. Starting at $n=1$ the free energies change rapidly with increasing length and become constant for lengths longer than the delocalization length. Both the reduction potentials and triplet energies can be understood as the sum of a free energy for a fixed polaron and a positional entropy. The positional entropy increases gradually with length beyond the delocalization length due the possible occupation sites of the charge or the triplet exciton. The results reinforce the view that charges and triplet excitons in conjugated chains exist as polarons and find that positional entropy can replace a popular empirical model of the energetics.
\end{abstract}

\section{Introduction}

The natures of charges and excited states in conjugated oligomers and polymers can determine performance of those molecules in molecular electronics, ${ }^{1}$ organic light-emitting 
diodes, ${ }^{2-3}$ or organic solar cells. ${ }^{4}$ The redox potentials and excited state energies determined as functions of length for conjugated oligomers provide insight to understand the electron and energy transfer in the conjugated polymers. Charges and excitons do not to span the entire lengths of long, conjugated molecules, but to delocalize partly to form polarons. ${ }^{5-8,9,10-11}$ As a consequence, we might expect their energies to become constant once the length of the oligomer exceeds the delocalization length of the polaron, and to be identical to those for long polymers. But the redox potentials in such as the oligofluorene ${ }^{7}$ and oligothiophene ${ }^{5,8}$ have been found to change slowly at lengths longer than the delocalization length of the polaron. A linear relation between these redox potentials and $1 / n$ has roots related to particles in a 1D boxes has been widely used. $5,7-8,12-19$ We propose here an alternate picture, in which the energy of the polaron becomes constant for chain lengths greater than the delocalization length $\left(n_{d}\right)$ while the free energy continues to change slowly due to the positional entropy arising because the polaron can reside at varied positions along the chain.

Entropy in three dimensions may be an important driver of charge separation in organic photovoltaic cells. It may explain, in substantial part, the mystery of how photo-generated electrons and holes escape from each other in these low-dielectric media. ${ }^{20-22}$ Here in the simpler one-dimensional case we test the role of entropy on redox potentials described above through measurements of the reduction potentials and the triplet free energies $\Delta G^{\circ} \mathrm{T}$ of oligo(9,9dihexyl)fluorene with repeat-unit lengths of 1-10 and 57. Both were determined by bimolecular electron transfer ET or triplet energy transfer (TT) equilibria in solution. It is crucial that this method is capable of measuring one-electron reduction potentials for molecules such as $F_{n}(n=1$ 10,57), which are not readily measured by electrochemical techniques for lengths longer than $7 .^{7}$ The results are consistent with the simple picture that the redox potentials and $\Delta \mathrm{G}^{\circ}$ are sums of the electronic energies and entropic energies from positional entropy. This simple picture can be applied to oligomers, polymers and possibly to their solid films.

\section{Experiments}

Samples were prepared under an argon atmosphere in purified THF, toluene, or $p$-xylene and placed in airtight quartz cells with 5 or $20 \mathrm{~mm}$ path lengths. THF was purified by a commercial THF purifier (Solvent Purification System, VAC Inc.). Toluene and $p$-xylene were passed through a silica gel column to remove water and impurities. Chemicals were used as received without further purification. Syntheses of oligo(9,9-dihexyl)fluorenes, $F_{n}(n=1-10,57)$, were described previously. ${ }^{23}$ For pulse radiolysis, $<50$ ps, 9 $\mathrm{MeV}$ electron pulse was provided by Laser Electron Accelerator Facility ${ }^{24}$ at Brookhaven National Laboratory. The probe light source is a Xenon arc lamp. The probe wavelengths are selected by optical interference filters with $10 \mathrm{~nm}$ band width. The optical detector is a silicon photodiode (EG\&G FND-100, 2 ns response time). The signals were collected with LeCroy 8620A, 640Zi, or HRO 66Zi digitizing oscilloscopes.

\section{Results}


Electron Transfer Equilibria These experiments used mixtures of a donor (D) and an acceptor (A) in THF solution. $D$ is usually a fluorene oligomer or polymer and $A$ is a molecule with a known redox potential; all will be listed in tables below. Because we seek equilibria the labels $D$ and $A$ are convenient, but interchanging the labels would have no effect. Pulse radiolysis creates solvated electrons which rapidly attach to the solutes. The radiation chemistry in THF is described in Section S1 of the supporting information (SI). In addition to homogeneous electrons the solutes also capture geminate electrons, those inside the Onsager radius, ${ }^{25}$ to create geminate anions. Geminate anions decay rapidly by recombination with solvated protons created by the THF radical cations ${ }^{26}$ (Reaction R5 of the SI). Those geminate decays are seen in the first $100 \mathrm{~ns}$ in Figure 1, which gives an example of data used to determine equilibrium constants, $\mathrm{K}_{\text {eq. }}$. After $\sim 100 \mathrm{~ns}$ most anions are homogeneous anions, which recombine much more slowly with solvated protons. Because ionizing radiation ionizes solvent almost exclusively, the yield of ions does not depend on the solute concentration, which are dilute (the samples are $>>99 \%$ solvent). Thus for each of the three traces in Figure 1 the concentration of anions is the same so $\mathrm{K}_{\text {eq }}$ is readily evaluated utilizeing geminate or homogeneous anions. In practice we evaluated $\mathrm{K}_{\text {eq }}$ at times $\gg>100$ ns where almost all anions are homogeneous. Because the solute concentrations are high enough to capture almost all homogeneous electrons, the concentration of anions is nearly constant from sample to sample. The concentration of the $D$ is typically much greater than that of the $A$, so most solvated electrons created by pulse radiolysis will attach to the $D$ and then transfer to $A, D^{{ }^{*}+}+A \rightleftharpoons D+A^{\circ-}$.

The equilibrium constants $\left(\mathrm{K}_{\text {eq }}\right)$, reduction potentials $\left(\mathrm{E}^{0}\left(\mathrm{M}^{0 /-}\right)\right)$, and bimolecular electron transfer rate constants $\left(k_{\mathrm{ET}}\right)$ were determined from sets of data like those in Figure 1 . In this example, transstilbene $(E S)$ is the $D$ and $F_{8}$ is the $A$. The experiments determined the ratio of the extinction coefficients between the $\mathrm{ES}^{--}$and $\mathrm{F}_{8}{ }^{--}$at the $710 \mathrm{~nm}$ absorption maximum of $\mathrm{ES}^{\circ-}$. Because the concentration of anions is the same in each trace, the ratio of extinction coefficients at $710 \mathrm{~nm}$ was readily obtained from the ratio of the $\mathrm{ES}$ and $\mathrm{F}_{8}$ traces. Extinction coefficient ratios found here were consistent with those from Pederson and Zaikowski. ${ }^{9,}{ }^{27} \mathrm{~K}_{\mathrm{eq}}=[\mathrm{D}]\left[\mathrm{A}^{\left.{ }^{-}\right]}\right] /\left[\mathrm{D}^{*-}\right][\mathrm{A}]$ was determined for mixtures of ES and $\mathrm{F}_{8}$ from kinetic traces using the ratio of absorbances of $\mathrm{ES}^{{ }^{-}}, \mathrm{F}_{8}{ }^{--}$at $710 \mathrm{~nm}$ and the determined ratio of extinction coefficients. We calculated the free energy change for the electron transfer reaction $\Delta \mathrm{G}^{\circ}=-\mathrm{R} \ln \left(\mathrm{K}_{\text {eq }}\right)$. Because $\Delta \mathrm{G}^{\circ}=$ $E^{0}\left(F_{8}{ }^{0 /-}\right)-E^{0}\left(M^{0 /-}\right), E^{0}\left(F_{8}{ }^{0 /-}\right)$ was obtained using $E^{0}\left(M^{0 /-}\right)$, the known reduction potential for the reference molecule, in this case ES. $k_{\mathrm{ET}}$ is determined by observing the slow decays of the $\mathrm{ES}^{-{ }^{-}}$with different $\mathrm{F}_{8}$ concentrations. 


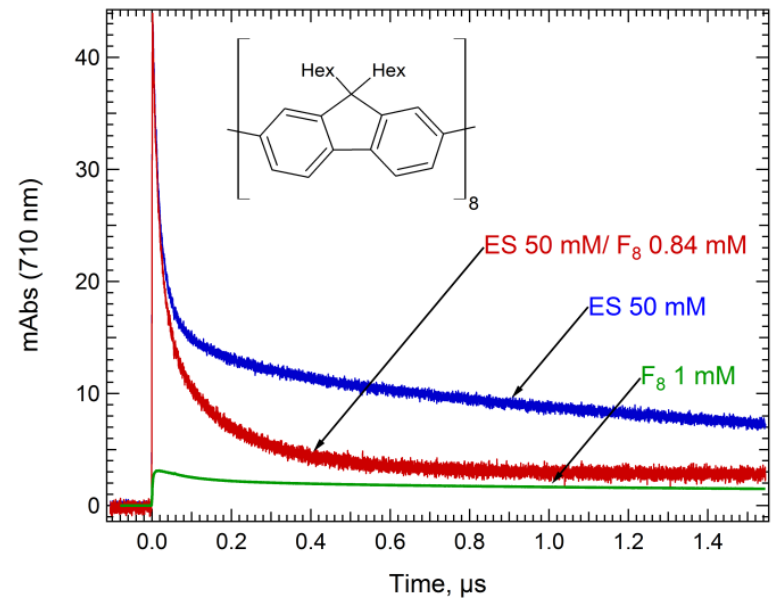

Figure 1. An example of transient absorption at the $710 \mathrm{~nm}$ absorption maximum for trans-stilbene anion, $\mathrm{ES}^{{ }^{-}}$, to measure $\mathrm{K}_{\text {eq }}$ for the electron transfer reaction $\mathrm{ES}^{\cdot-}+\mathrm{F}_{8} \rightleftharpoons \mathrm{ES}+\mathrm{F}_{8}{ }^{\cdot-}$ in THF. Decays in the first 100 ns are due to geminate recombination (see text). The kinetic trace for $F_{8}$ without stilbene (ES) has been corrected for a small contribution from $\mathrm{F}_{8}$ triplets. In mixtures, absorption from ES ${ }^{--}$decays to a final absorption higher than in $1 \mathrm{mM} \mathrm{F}_{8}$ alone as equilibrium is established.

To measure the $\mathrm{E}^{0}\left(\mathrm{~F}_{1}{ }^{0 /-}\right)$ we used phenanthrene as the reference, and determined $\mathrm{K}_{\text {eq }}$ from data collected at the $650 \mathrm{~nm}$, absorption maximum of $\mathrm{F}_{1}{ }^{\cdot-} \cdot{ }^{28}$ Trans-stilbene (ES) was the reference molecule for $E^{0}\left(F_{n}{ }^{0 /-}, n=2-9\right) ; 1-m e t h y l p y r e n e ~(M e P y)$ was the reference molecule for $E^{0}\left(F_{n}{ }^{0 /-}, n=10,57\right)$. The $K_{\text {eq }}$ were determined from data collected at the absorption maxima of $\mathrm{ES}^{\circ-}$ and MePy ${ }^{\circ-}$. A potential complication comes from small yields of triplets created by pulse radiolysis. The contributions of triplets was noticed because the time-dependence of their decay is different than that of anions. We quantified their presence by taking spectra and making use of their known extinction coefficients. ${ }^{29-31}$ When these triplets absorb at the wavelengths where the anions are measured, they can introduce an error. In samples containing $E S, F_{n}$ triplets were rapidly removed by triplet energy transfer to ES, which has a lower triplet energy, $\Delta \mathrm{G}_{\mathrm{T}}^{\circ}=2.137 \mathrm{eV}{ }^{32}$ compared to those for oligofluorenes (see Table 2). This transfer forms ES triplets which do not absorb at $710 \mathrm{~nm}$ and which have a very short lifetime ( 100 ns). ${ }^{33}$ In samples without ES, we measured the concentrations of ${ }^{3} \mathrm{~F}_{\mathrm{n}}{ }^{*}$ at their maximum absorption and applied the corrections to the 710 $\mathrm{nm}$ data based on measured extinction coefficients of the ${ }^{3} \mathrm{~F}_{\mathrm{n}}{ }^{*}$ at the two wavelengths. The measured $\mathrm{K}_{\mathrm{eq}}$ and $\mathrm{E}^{0}\left(\mathrm{~F}_{\mathrm{n}}{ }^{0 /-}, \mathrm{n}=1-10,57\right)$ are given in Table 1.

Table 1. Reduction potentials $\mathrm{E}^{0}\left(\mathrm{M}^{0 /-}\right)$, bimolecular electron transfer rate constants $k_{\mathrm{ET}}$, and equilibrium constants $K_{\text {eq }}$ for the electron transfer reactions of $F_{n}(n=1-10,57)$.

\begin{tabular}{|c|c|c|c|c|c|}
\hline Name & $\mathrm{E}^{0}\left(\mathrm{~F}_{\mathrm{n}}{ }^{0 /-}\right)$ vs. $\mathrm{Fc}^{0 /+}(\mathrm{V})$ & Reactions & {$[\mathrm{D}] /[\mathrm{A}](\mathrm{mM})$} & $k_{\mathrm{ET}}\left(\mathrm{M}^{-1} \mathrm{~s}^{-1}\right)^{b}$ & $\mathrm{Keq}^{b}$ \\
\hline $\mathrm{F}_{1}$ & $-3.098( \pm 0.014)^{a}$ & $\mathrm{~F}_{1}{ }^{\bullet-}+\mathrm{Phe} \rightleftharpoons \mathrm{F}_{1}+\mathrm{Phe}^{\bullet-}$ & $100 / 0.062-0.52$ & $1.6 \times 10^{10}$ & $2548( \pm 1080)$ \\
\hline $\mathrm{F}_{2}$ & $-2.818( \pm 0.016)^{a}$ & $\mathrm{Phe}^{\bullet-}+\mathrm{F}_{2} \rightleftharpoons \mathrm{Phe}+\mathrm{F}_{2}{ }^{\bullet-}$ & 20/0.244-1.111 & $1.4 \times 10^{10}$ & $22( \pm 8)$ \\
\hline
\end{tabular}




\begin{tabular}{|c|c|c|c|c|c|}
\hline & & $\mathrm{F}_{2}{ }^{\bullet-}+\mathrm{ES} \rightleftharpoons \mathrm{F}_{2}+\mathrm{ES}^{\bullet-}$ & $30 / 0.07-0.6$ & $1.0 \times 10^{10}$ & $39( \pm 11)$ \\
\hline$F_{3}$ & $-2.642( \pm 0.005)^{a}$ & $\mathrm{ES}^{\cdot-}+\mathrm{F}_{3} \rightleftharpoons \mathrm{ES}+\mathrm{F}_{3}{ }^{\bullet-}$ & 20/0.1-1.85 & $6.3 \times 10^{9}$ & $24( \pm 4)$ \\
\hline $\mathrm{F}_{4}$ & $-2.594( \pm 0.003)^{a}$ & $\mathrm{ES}^{\cdot-}+\mathrm{F}_{4} \rightleftharpoons \mathrm{ES}+\mathrm{F}_{4}^{\cdot-}$ & 20/0.04-0.41 & $8.6 \times 10^{9}$ & $161( \pm 20)$ \\
\hline$F_{5}$ & $-2.583( \pm 0.008)^{a}$ & $\mathrm{ES}^{\bullet-}+\mathrm{F}_{5} \rightleftharpoons \mathrm{ES}+\mathrm{F}_{5}{ }^{\bullet-}$ & $50 / 0.2-1.48$ & $9.7 \times 10^{9}$ & $225( \pm 71)$ \\
\hline$F_{6}$ & $-2.572( \pm 0.007)^{a}$ & $\mathrm{ES}^{\cdot-}+\mathrm{F}_{6} \rightleftharpoons \mathrm{ES}+\mathrm{F}_{6^{-}}{ }^{-}$ & $50 / 0.1-0.74$ & $1.3 \times 10^{10}$ & $366( \pm 99)$ \\
\hline$F_{7}$ & $-2.557( \pm 0.006)^{a}$ & $\mathrm{ES}^{\cdot-}+\mathrm{F}_{7} \rightleftharpoons \mathrm{ES}+\mathrm{F}_{7}^{\bullet-}$ & $50 / 0.1-0.84$ & $2.0 \times 10^{10}$ & $656( \pm 163)$ \\
\hline$F_{8}$ & $-2.542( \pm 0.007)^{a}$ & $\mathrm{ES}^{\cdot-}+\mathrm{F}_{8} \rightleftharpoons \mathrm{ES}+\mathrm{F}_{8}{ }^{\bullet-}$ & $50 / 0.1-0.84$ & $2.2 \times 10^{10}$ & $1191( \pm 273)$ \\
\hline $\mathrm{F}_{9}$ & $-2.535( \pm 0.010)^{a}$ & $\mathrm{ES}^{\bullet-}+\mathrm{F}_{9} \rightleftharpoons \mathrm{ES}+\mathrm{F}_{9}^{\cdot-}$ & $50 / 0.05-0.366$ & $3.9 \times 10^{10}$ & $1581( \pm 525)$ \\
\hline $\mathrm{F}_{10}$ & $-2.513( \pm 0.002)^{a}$ & $\mathrm{MePy}{ }^{\bullet-}+\mathrm{F}_{10} \rightleftharpoons \mathrm{MePy}+\mathrm{F}_{10} 0^{--}$ & $0.2-7.8 / 1$ & $1.95 \times 10^{10}$ & $48( \pm 5)$ \\
\hline$F_{57}$ & $-2.476( \pm 0.002)^{d}$ & $\mathrm{MePy}{ }^{\bullet-}+\mathrm{F}_{57} \rightleftharpoons \mathrm{MePy}+\mathrm{F}_{57^{--}}$ & $15 / 0.027-0.12$ & $1.22 \times 10^{11}$ & $202( \pm 16)$ \\
\hline ePy & $-2.612( \pm 0.005)^{a}$ & $\mathrm{ES}^{\bullet-}+\mathrm{MePy} \rightleftharpoons \mathrm{ES}+\mathrm{MePy}{ }^{\bullet-}$ & 50/0.83-5.83 & $1.01 \times 10^{10}$ & $81( \pm 14)$ \\
\hline
\end{tabular}

${ }^{a}$ The reduction potential of trans-stilbene, $\mathrm{E}^{0}\left(\mathrm{ES}^{0 /-}\right)=-2.724 \mathrm{~V} \mathrm{vs}$. $\mathrm{Fc}^{0 /+}$ served as the reference. This value is based on $\mathrm{E}^{0}\left(\mathrm{ES}^{0 /-}\right)-\mathrm{E}^{0}\left(\mathrm{AC}^{0 /-}\right)=-0.22 \mathrm{~V}^{34}$ and $\mathrm{E}^{0}\left(\mathrm{AC}^{0 /-}\right)=-2.504 \mathrm{~V}$ vs. $\mathrm{FC}^{0 /+}$ in THF (AC=anthracene).$^{35}$

${ }^{b} k_{\mathrm{ET}}$ and $\mathrm{K}_{\text {eq }}$ for electron transfer from $\mathrm{D}^{\cdot-}$ to $\mathrm{A}$ are the root-mean-square values from 5 different [D]/[A] ratios.

c1-methylpyrene

${ }^{d} \mathrm{E}^{0}\left(\mathrm{MePy}^{0 /-}\right)=-2.600 \mathrm{~V}$ vs. $\mathrm{Fc}^{0 /+}$ as the reference. This value was measured by the bimolecular equilibria method with trans-stilbene as the reference. Like others in the table this measurement was in THF without electrolyte. Thus all the measurements from $\mathrm{F}_{3}-\mathrm{pF}_{57}$ used the same reference, although the phenanthrene reference for $F_{1}$ and $F_{2}$ used a measurement in THF with electrolyte.

Triplet Absorption Spectra. Pulse radiolysis in non-polar solvents is one of the best ways to produce triplets. ${ }^{36}$ The radiation chemistry in toluene and $p$-xylene is described in Section S1 of the SI. Figure 2 shows the triplet absorption spectra from pulse radiolysis of $F_{n}(n=2-6)$ in toluene containing $100 \mathrm{mM}$ of biphenyl. The triplet bands shift to longer wavelength until $n=5$. In aromatic solvents (Ar) such as toluene and $p$-xylene, large yields of the ${ }^{3} \mathrm{Ar}^{*}$ and ${ }^{1} \mathrm{Ar}^{*}$ are created by pulse radiolysis via the excitation, charge recombination, and intersystem crossing reactions (SI Reactions R6-R9). While the solvent triplet and singlet excited states are both short-lived ( $<20 \mathrm{~ns}$ ), they were both rapidly transferred to biphenyl, which has a long-lived triplet state $\tau=130 \mu \mathrm{s}^{37}$ a high triplet free energy $\Delta \mathrm{G}_{\mathrm{T}}{ }_{\mathrm{T}}=3.01 \mathrm{eV},{ }^{38}$ and a high triplet yield $\Phi_{\mathrm{T}}=0.84{ }^{39}$ so nearly all excited states become biphenyl triplets, which then transfer almost quantitatively to the oligofluorenes or polyfluorene. 


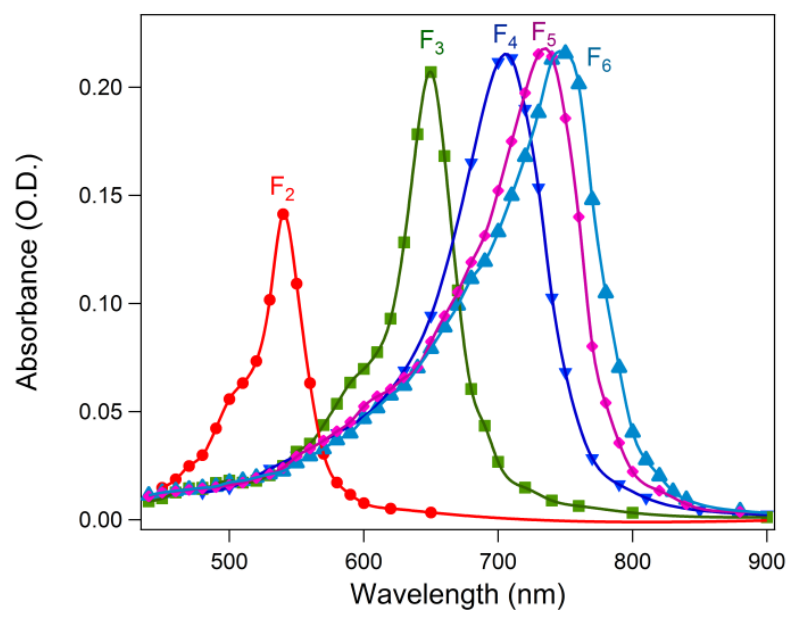

Figure 2. The triplet absorption spectra from pulse radiolysis of $F_{n}(n=2-6)$ in toluene with 100 mM of biphenyl.

Triplet Transfer Equilibria With the methods above and $100 \mathrm{mM}$ of the triplet energy donors, naphthalene or biphenyl, we could measure the equilibrium constants $K_{\text {eq }}=[D]\left[{ }^{3} A^{*}\right] /\left[{ }^{3} D^{*}\right][A]$ for triplet energy transfer ${ }^{3} D^{*}+A \rightleftharpoons D+{ }^{3} A^{*}$ in a manner analogous to that described above for electron transfer. The lifetime of naphthalene triplet is $175 \mu \mathrm{s}^{40} \Delta \mathrm{G}_{\mathrm{T}}^{\circ}=2.64 \mathrm{eV},{ }^{41}$ and $\Phi_{\mathrm{T}}=0.75,{ }^{39}$ so either naphthalene or biphenyl serves equally well. Figure 2 shows that the triplet absorption spectrum of $F_{3}$ is well-separated from those of other oligofluorenes, so triplet transfer to or from $F_{3}$ can readily be observed to obtain the $K_{\text {eq }}$ and bimolecular triplet transfer rate constant $\left(k_{\pi}\right)$. Figure 3 shows an example of triplet transfer from ${ }^{3} \mathrm{~F}_{3}{ }^{*}$ to $\mathrm{pF}_{57}$ to obtain the $\mathrm{K}_{\text {eq }}$ and $k_{\mathrm{TT}}$. Similar data was used in other reactions. Figure $\mathrm{S} 4$ in SI plots spectra for one such reaction. The $\Delta G_{T}^{\circ}$ of $F_{n}(n=2,4,5,7,10,57)$ with $\Delta G_{T}^{\circ}=2.276 e^{42}$ of $F A$ as the reference are reported in Table 2.

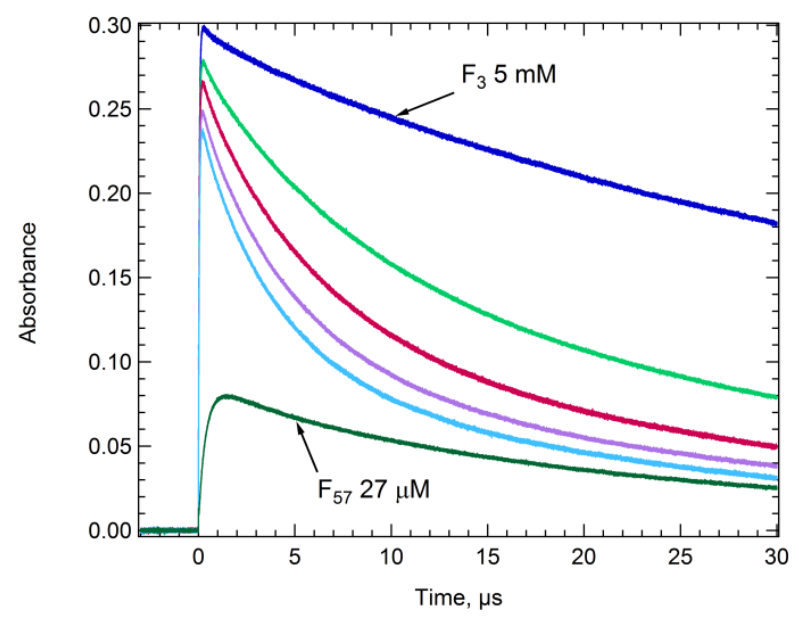

Figure 3. The equilibrium constant $\left(\mathrm{K}_{\text {eq }}\right)$ of the reaction, ${ }^{3} \mathrm{~F}_{3}{ }^{*}+\mathrm{pF}_{57} \rightleftharpoons \mathrm{F}_{3}+{ }^{3} \mathrm{~F}_{57}{ }^{*}$, was determined from the kinetic traces of $F_{3}(5 \mathrm{mM}), \operatorname{pF} 57(27 \mu \mathrm{M})$ and mixtures having $\left[F_{3}\right] /\left[p F_{57}\right]$ ratios of $151,83,56$ and 42 in p-xylene with $100 \mathrm{mM}$ of biphenyl at the $650 \mathrm{~nm}$ maximum of ${ }^{3} \mathrm{~F}_{3}{ }^{*}$. 
Table 2. Triplet free energy change, $\Delta \mathrm{G}^{\circ} \mathrm{T}$, for forming the lowest triplet excited state, the bimolecular triplet excitation transfer rate constants $\left(k_{\mathrm{TT}}\right)$, and equilibrium constants $\left(\mathrm{K}_{\text {eq }}\right)$ of triplet energy transfer reactions for $F_{n}(n=2,4,5,7,10,57)$.

\begin{tabular}{|c|c|c|c|c|c|}
\hline Name & $\Delta \mathrm{G}^{\circ}{ }_{\mathrm{T}}(\mathrm{eV})$ & Reactions & {$[\mathrm{D}] /[\mathrm{A}](\mathrm{mM})$} & $K_{\Pi}\left(\mathrm{M}^{-1} \mathrm{~s}^{-1}\right)^{a}$ & $\mathrm{Keq}^{a}$ \\
\hline $\mathrm{F}_{1}$ & $2.94^{17}$ & & & & \\
\hline $\mathrm{F}_{2}$ & $2.411^{d}$ & ${ }^{3} \mathrm{~F}_{2}{ }^{*}+\mathrm{F}_{3} \rightleftharpoons \mathrm{F}_{2}+{ }^{3} \mathrm{~F}_{3}{ }^{*}$ & $20 / 1$ & $2.2 \times 10^{8}$ & $41.14^{b}$ \\
\hline $\mathrm{F}_{3}$ & $2.316( \pm 0.004)^{d}$ & ${ }^{3} \mathrm{~F}_{3}{ }^{*}+\mathrm{FA} \rightleftharpoons \mathrm{F}_{3}+{ }^{3} \mathrm{FA}^{*}$ & $1 / 0.04-0.20$ & $8.69 \times 10^{8}$ & $4.78( \pm 0.71)^{c}$ \\
\hline $\mathrm{F}_{4}$ & $2.288^{d}$ & ${ }^{3} \mathrm{~F}_{3}{ }^{*}+\mathrm{F}_{4} \rightleftharpoons \mathrm{F}_{3}+{ }^{3} \mathrm{~F}_{4}{ }^{*}$ & $8.5 / 0.85$ & $1.2 \times 10^{8}$ & $2.93^{b}$ \\
\hline $\mathrm{F}_{5}$ & $2.263^{d}$ & ${ }^{3} \mathrm{~F}_{3}{ }^{*}+\mathrm{F}_{5} \rightleftharpoons \mathrm{F}_{3}+{ }^{3} \mathrm{~F}_{5}{ }^{*}$ & $8.85 / 1.93$ & $1.5 \times 10^{8}$ & $8.07^{b}$ \\
\hline $\mathrm{F}_{7}$ & $2.237( \pm 0.009)^{d}$ & ${ }^{3} \mathrm{~F}_{3}{ }^{*}+\mathrm{F}_{7} \rightleftharpoons \mathrm{F}_{3}+{ }^{3} \mathrm{~F}_{7}{ }^{*}$ & $0.26 / 0.06-0.55$ & $4.05 \times 10^{8}$ & $21.6( \pm 4 .)^{c}$ \\
\hline $\mathrm{F}_{10}$ & $2.228( \pm 0.014)^{d}$ & ${ }^{3} \mathrm{~F}_{3}{ }^{*}+\mathrm{F}_{10} \rightleftharpoons \mathrm{F}_{3}+{ }^{3} \mathrm{~F}_{10}{ }^{*}$ & $0.65 / 0.05-0.44$ & $4.10 \times 10^{8}$ & $31( \pm 10)^{c}$ \\
\hline$F_{57}$ & $2.178( \pm 0.024)^{d}$ & ${ }^{3} \mathrm{~F}_{3}{ }^{*}+\mathrm{F}_{57} \rightleftharpoons \mathrm{F}_{3}+{ }^{3} \mathrm{~F}_{57}{ }^{*}$ & 5/0.03-0.11 & $2.35 \times 10^{9}$ & $220^{c, e}$ \\
\hline
\end{tabular}

${ }^{a} k_{\Pi \pi}$ and $K_{\text {eq }}$ for triplet energy transfer from D to A. Uncertainties on $k_{\text {EXT }}$ are $\pm 20 \%$.

${ }^{b}$ Measured in toluene with $100 \mathrm{mM}$ of naphthalene (see text). Uncertainties are $\pm 30 \%$ )

${ }^{c}$ Measured in $p$-xylene with $100 \mathrm{mM}$ of biphenyl (see text) and a root-mean-square values from 5 different $[D] /[A]$ ratios.

${ }^{d}$ Used the $\Delta \mathrm{G}^{\circ}{ }_{\mathrm{T}}=2.276 \mathrm{eV}^{42}$ of fluoranthene (FA), determined by an equilibrium method, as the reference (see text).

${ }^{e} \mathrm{~F}_{3}$ and $\mathrm{pF}_{57}$ triplets decayed at different rates creating larger uncertainties, $\mathrm{K}_{\mathrm{eq}}=220(+200,-100)$.

Computed Anion and Triplet Energies. Table 3 presents the standard free energy changes and enthalpies for the anions and triplets of $F_{n}(n=1-10)$ computed by the long-range-corrected $\omega P B E / 6-31 G(d)(\omega=0.1$ bohr $^{-1}$ ) with the SMD solvation model ${ }^{43}$ for THF. Earlier work found that $\omega$ PBE with $\omega=0.1$ bohr $^{-1}$ successfully described excitation energies and delocalization lengths in $F_{n}$ neutrals and radical anions. ${ }^{9}$ Here we add additional data on anion free energies (redox potentials) and $\Delta \mathrm{G}^{\circ}{ }_{\mathrm{T}}$. In computing the triplets we found that optimization under symmetry constraints resulted in slightly higher triplet energies for ${ }^{3} \mathrm{~F}_{\mathrm{n}}{ }^{*}$ for $n=$ odd than for $n=$ even (see Table S2); these energies are the computed electronic energy differences between the optimized ground and lowest triplet-excited states. The optimized structures found in the computations on triplets contained two nearly-coplanar repeat units. $F_{n}$ with odd $n$, like $F_{3}$, cannot have symmetric structures with two nearly coplanar fluorenes, and a larger dihedral for the third. The calculations for both anions and triplets were therefore performed with symmetry disabled.

Computed estimations of the standard free energy for the anion or triplet formation were obtained from frequency calculations performed by Gaussian 09 D.1; $;^{44}$ these standard free energies do 
not include the "positional entropy", described below in the discussion section. The enthalpies and free energies for forming anions and triplets change rapidly with increasing oligomer length, but more slowly after $F_{4}$ (anions) or $F_{3}$ (triplets). Computed molecular orbitals of the $F_{10}$ anion and triplet shown in Figure 4 suggest that the delocalization lengths, $n_{d}$, are near 4 repeat-units for the anion and 3 for the triplet. Because computations describe polarons that do not change length for oligomers longer than $n_{\mathrm{d}}$, a reasonable hypothesis is that these computed internal entropies would also become constant for $n>n_{d}$. We hoped the calculations would test this hypothesis. The computed vibrational entropies $\left(\Delta \mathrm{S}_{\mathrm{vib}}\right)$ for oligomers longer than the $n_{\mathrm{d}}$ (Table S3 of the SI) instead changed irregularly with the length, and calculations sometimes failed to converge, indicating some computational problem even though the frequency analyses found no imaginary vibration frequencies. The computed results therefore did not support the hypothesis, but neither did they find any trend to refute it. They did find that the computed internal vibrational entropy changes were smaller than the positional entropies. To compute the free energies for the oligomers longer than the $n_{\mathrm{d}}$, we therefore took the formation enthalpy, and averages of entropic contributions to the formation free energy from the successful calculations (see Table S3). These averages were $\mathrm{T} \Delta \mathrm{S}_{\mathrm{vib}}=38 \pm 33 \mathrm{meV}$ for forming an anion and $\mathrm{T} \Delta \mathrm{S}_{\mathrm{vib}}=57 \pm 9 \mathrm{meV}$ for forming a triplet; the uncertainties are standard deviations.

Table 3. For $F_{n}(n=1-8,10,57)$, the computed standard free energy changes, $\Delta G_{\text {calc }}$ and enthalpies $\Delta \mathrm{H}_{\text {calc }}$ of the anions and triplets by the long-range corrected $\omega \mathrm{PBE} / 6-31 \mathrm{G}(\mathrm{d})\left(\omega=0.1 \mathrm{bohr}^{-1}\right)$ with the SMD ${ }^{43}$ solvation model for THF with symmetry disabled. For anions $\Delta H_{\text {calc }}=\Delta H\left(F_{n}{ }^{-1}\right)-\Delta H\left(F_{n}\right)$, and $\Delta \mathrm{H}_{\text {calc }}=\Delta H\left({ }^{3} \mathrm{~F}_{\mathrm{n}}{ }^{*}\right)-\Delta \mathrm{G}^{\circ}\left(\mathrm{F}_{\mathrm{n}}\right)$ for triplets; $\Delta \mathrm{G}_{\text {calc }}=\Delta \mathrm{H}_{\text {calc }}-\mathrm{T} \Delta \mathrm{S}$ (see Table S3 for the details).

\begin{tabular}{|c|c|c|c|c|}
\hline \multirow{2}{*}{ Name } & \multicolumn{2}{|c|}{ Anion } & \multicolumn{2}{c|}{ Triplet } \\
\cline { 2 - 5 } & $\Delta \mathrm{G}_{\text {calc }}(\mathrm{eV})$ & $\Delta \mathrm{H}_{\text {calc }}(\mathrm{eV})$ & $\Delta \mathrm{G}_{\text {calc }}(\mathrm{eV})$ & $\Delta \mathrm{H}_{\text {calc }}(\mathrm{eV})$ \\
\hline $\mathrm{F}_{1}$ & -1.187 & -1.135 & 2.815 & 2.897 \\
\hline $\mathrm{F}_{2}$ & -1.647 & -1.622 & 2.382 & 2.439 \\
\hline $\mathrm{F}_{3}$ & -1.784 & -1.733 & 2.305 & 2.374 \\
\hline $\mathrm{F}_{4}$ & -1.816 & -1.778 & 2.263 & 2.345 \\
\hline $\mathrm{F}_{5}$ & -1.852 & -1.787 & 2.275 & 2.361 \\
\hline $\mathrm{F}_{6}$ & -1.843 & -1.787 & 2.265 & 2.347 \\
\hline $\mathrm{F}_{7}$ & -1.851 & -1.794 & 2.256 & 2.338 \\
\hline $\mathrm{F}_{8}$ & -1.857 & -1.801 & & \\
\hline $\mathrm{F}_{9}$ & & & 2.262 & 2.336 \\
\hline $\mathrm{F}_{10}$ & -1.852 & -1.796 & 2.260 & 2.341 \\
\hline $\mathrm{F}_{57}$ & $-1.851^{a}$ & $-1.795^{a}$ & $2.265^{a}$ & $2.347^{a}$ \\
\hline
\end{tabular}


${ }^{a}$ For $\mathrm{pF}_{57}$ we report the root-mean-square values from $F_{n}(n=6-8,10)$ for anions and $F_{n}(n=4-7,9,10)$ for triplets.

(a)

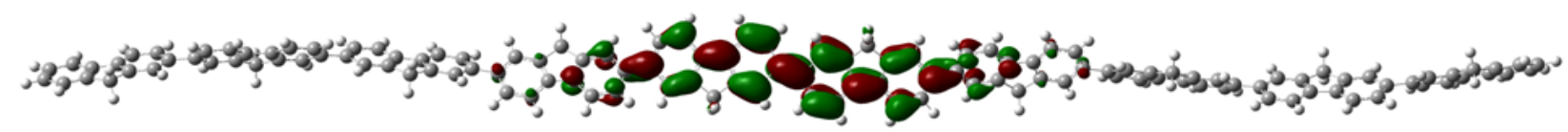

(b)

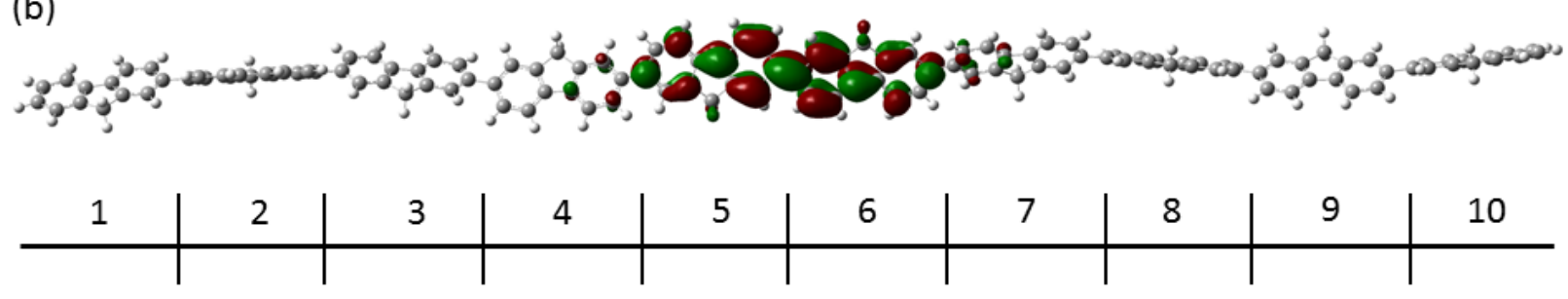

Figure 4. The highest occupied molecular orbitals (HOMO's) of $F_{10}$ (a) anion and (b) triplet computed by the long-range corrected $\omega \operatorname{PBE}\left(\omega=0.1 \mathrm{Bohr}^{-1}\right) / 6-31 \mathrm{G}(\mathrm{d})$ with the $\mathrm{SMD}^{43}$ solvation model for THF and symmetry disabled. The HOMO's suggest 4 and 3 repeat-unit long of polaron delocalization lengths for the anion and triplet.

\section{Discussion}

Reduction Potentials. Figure 5 a plots the measured $\mathrm{E}^{0}\left(\mathrm{~F}_{\mathrm{n}}{ }^{0 /-}, \mathrm{n}=1-10,57\right)$ which become less negative (easier reduction) as $n$ increases. Similarly $\mathrm{Chi}^{7}$ found that the oxidation potentials of $\mathrm{F}_{n}(n=2-7)$ become less positive (easier oxidation) as $n$ increases and predicted that the $\mathrm{E}^{0}\left(\mathrm{~F}_{\mathrm{n}}{ }^{0 /-}\right)$ would become less negative with increasing $n$ mirroring the behavior of the oxidation potentials. Elandaloussi ${ }^{12}$ reported similar observations on the oxidation potentials of oligothienylenevinylenes. A comparison of potentials reported here for reduction with those reported by $\mathrm{Chi}^{7}$ for oxidation of $\mathrm{F}_{\mathrm{n}}$ shown in Figure $\mathrm{S} 5$ of the $\mathrm{SI}$ supports the mirror image behavior predicted by $\mathrm{Chi}^{7}$ which may be due to the symmetric bonding and antibonding molecular orbitals of conjugated oligomers predicted by the molecular orbital theory and similar solvation energies of the anions and cations. 

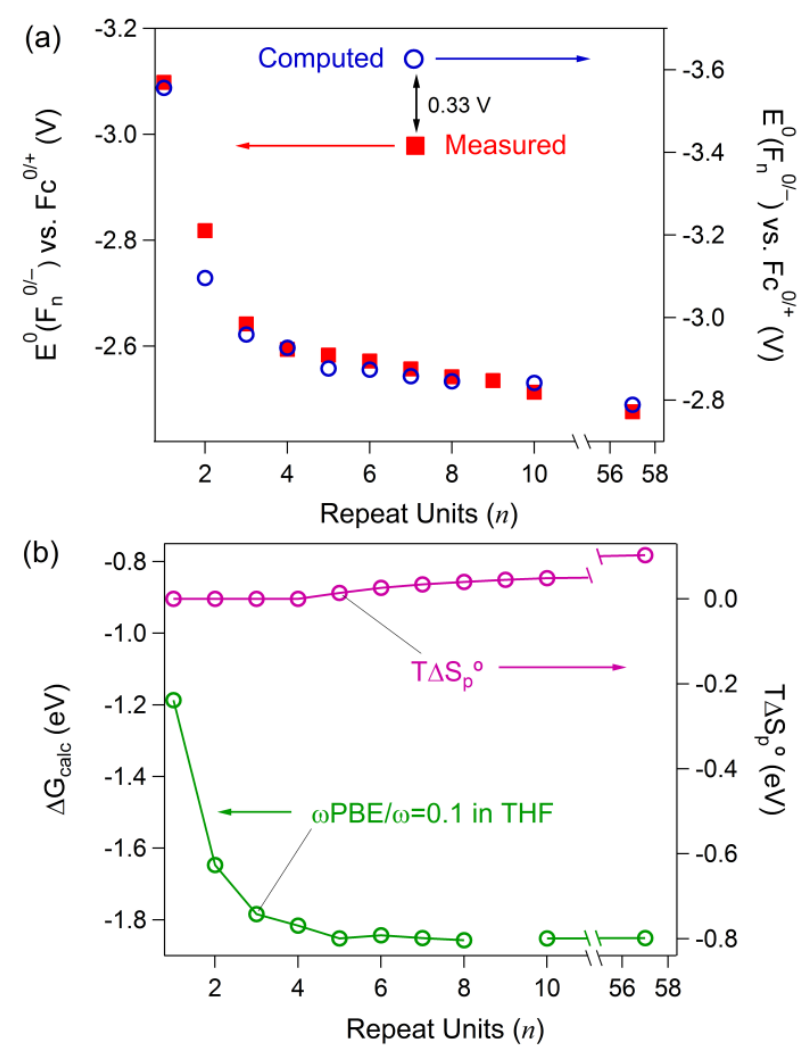

Figure 5. Plots of $(a)$ the measured $(\square)$ and computed $(O)$ reduction potentials $E^{0}\left(F_{n}{ }^{0 /-}\right)$ vs. the length of the oligomer in the repeat units $(n)$. The computed $E^{0}\left(F_{n}{ }^{0 /-}\right)=-\left(\Delta G_{\text {calc }}{ }^{-}\right.$ $\left.\left.\Delta \mathrm{G}_{\text {calc }}(\mathrm{Fc})-\mathrm{T} \Delta \mathrm{S}_{\mathrm{p}}{ }^{0}\right)\right] / e$. Here $\Delta \mathrm{G}_{\text {calc }}$ is the computed formation free energy for the anion in THF as in Table 3, $\Delta \mathrm{G}_{\text {calc }}(\mathrm{Fc})$ is the similarly computed free energy change for reduction of $\mathrm{Fc}^{+}$in $\mathrm{THF}$, and $\Delta \mathrm{S}_{\mathrm{p}}{ }^{0}$ is the positional entropy calculated by Eq. 1 with the delocalization length $n_{\mathrm{d}}=4.3$ repeat units. (b) The contributions of $\Delta G_{\text {calc }}$ (green) and positional entropy ( $T \Delta S_{p}{ }^{0} ; T=298 \mathrm{~K}$, purple) of $F_{n}$ $(n=1-8,10,57)$ vs. $n$. The $\Delta S_{p}{ }^{0}$ of $F_{n}(n=1-4)$ are assumed to be zero (see text).

Figure 5 a shows a rapid change of the measured $\mathrm{E}^{0}\left(\mathrm{~F}_{\mathrm{n}}{ }^{0 /-}, \mathrm{n}=1-4\right)$ and a slower change of the measured $E^{0}\left(F_{n}{ }^{0 /-}, n=5-10\right)$. The offset of the measured (left) and computed (right) vertical axes indicates an error of $-0.33 \mathrm{~V}$ in the absolute estimates of the computed energetics that will be discussed below. Figure $5 b$ shows that the measured potentials can be explained by a simple picture in which the standard free energy changes $\left(\Delta G^{0}\right)$ of anion is the sum of the computed standard free energy change $\left(\Delta G_{\text {calc }}\right)$ and a free energy change from positional entropy $\left(T \Delta S_{p}{ }^{0}\right)$, where $\mathrm{T}$ is temperature. The $\Delta \mathrm{G}_{\text {calc }}$, estimated by the DFT computations, are the free energy differences between the neutral molecules and their anions. From measurements of absorption spectra of $\mathrm{F}_{n}{ }^{--}(\mathrm{n}=2-10)$, Zaikowski ${ }^{9}$ concluded that the $n_{d}$ of the electron was 4.3 repeat units. With increasing $n$, the $\Delta \mathrm{G}_{\text {calc }}$ changes rapidly until $n=n_{\mathrm{d}}$ and then remains almost constant. For long oligomers with $n>n_{\mathrm{d}}$, if we assume that the charge can move freely along oligomer, then a positional entropy $\left(\Delta S_{p}{ }^{0}\right)$ will arise from the number of the possible positions of the charge along the oligomer. ${ }^{9,45}$ In a similar spirit we used a simple permutation to calculate the $\Delta \mathrm{S}_{\mathrm{p}}{ }^{0}$ treating 
the charge as a having a length of $n_{d}=4.3$ repeat units ${ }^{9}$ and the oligomers as a chain with a finite length in $n$ repeat units (eq 1 ).

$$
\Delta \mathrm{S}_{\mathrm{p}}^{0}=k_{\mathrm{B}} \ln \left(n-n_{d}+1\right)
$$

The $T \Delta S_{p}{ }^{0}$ for $F_{n}{ }^{0 /-}, n=5-10$, from eq 1 , are given in Table 4 and plotted in Figure $5 b$. In $F_{n}(n=1-4)$, the delocalization length is confined by the length of the oligomer, $n . \Delta S_{p}{ }^{0}$ is assumed to be zero because there is only one possible position for the charge. The computed reduction potentials in Figure $4 a$, which are the sums of $\Delta G_{\text {calc }}$ and $T \Delta S_{p}{ }^{0}$ from eq 1 are in good accord with the measured reduction potentials. The $\Delta \mathrm{G}_{\text {calc }}$ of anions in Table 1 are the computed free energy changes for forming anions in THF from electrons in vacuum. To compare with the experimental data we computed the reduction potential of ferrocenium $\left(\mathrm{Fc}^{\circ+}\right)$ from the free energy difference between $\mathrm{Fc}$ and $\mathrm{Fc}^{\circ+}$ in THF. This computed ( $\omega \mathrm{PBE} / 6-31 \mathrm{G}(\mathrm{d}), \omega=0.1$ ) value, $-4.743 \mathrm{~V}$, provides an estimate for $\mathrm{E}^{0}\left(\mathrm{Fc}^{0 /+}\right)$ in THF vs. $\mathrm{e}^{-}$in vacuum. This computed estimate is $\sim 0.50$ $\mathrm{V}$ less negative than the electrochemical estimate, $\mathrm{E}^{0}\left(\mathrm{Fc}^{0 /+}\right)=-5.245 \mathrm{~V}$ vs. $\mathrm{e}^{-}$in vacuum, based on $\mathrm{E}^{0}\left(\mathrm{Fc}^{0 /+}\right)$ $=0.545 \mathrm{~V}$ vs. SCE in $\mathrm{THF}^{46-47}$ and $-4.7 \mathrm{eV}$ for the Fermi level of the SCE in aqueous solution vs. $\mathrm{e}^{-}$in vacuum. ${ }^{48}$ Computed estimates for $E^{0}\left(\mathrm{~F}_{\mathrm{n}}{ }^{0 /-}, \mathrm{n}=1-8,10,57\right)$ were plotted on the right axis of Figure 5 a vs. the computed $\mathrm{E}^{0}\left(\mathrm{Fc}^{0 /+}\right)$.

The computed values of $\mathrm{E}^{0}\left(\mathrm{~F}_{\mathrm{n}}{ }^{0 /-}, \mathrm{n}=2-8,10,57\right)$ are an excellent match to the length-dependence of the experimental values, but are $\sim 0.33 \mathrm{~V}$ more negative as indicated by the offset of the right vertical axis. The $\sim 0.33 \mathrm{~V}$ difference may arise from errors in computations of the $\Delta \mathrm{G}_{\text {calc }}$ and from errors in computations of the reference potential $\mathrm{E}^{0}\left(\mathrm{Fc}^{0 /+}\right)$. Both were computed with long-range corrected $\omega \mathrm{PBE}$ $\left(\omega=0.1 \mathrm{bohr}^{-1}\right)$. While this long-range corrected functional was found to be effective for delocalized state, self-interaction errors may make it less accurate for smaller molecules like ferrocene. We have also not accounted for a difference that will arise because the experimental values were based on equilibria in the absence of electrolyte, while the reference reduction potentials were from electrochemical measurements in the presence of electrolyte. The results show that the length-dependence of $E^{0}\left(F_{n}{ }^{0 /-}, n=1-10,57\right)$ can be described well as the sum of the $\Delta G_{\text {calc }}$ and position-entropic energy, but the goal of an accurate prediction of the absolute potentials remains only roughly fulfilled. This simple picture of the $E^{0}\left(F_{n}{ }^{0 /-}\right)$ described here includes positional entropy in addition to internal entropy changes estimated by the frequency calculation. Because the implicit continuum model such as SMD model ${ }^{43}$ ignores the microscopic solute-solvent interaction, ${ }^{49}$ the solvation entropy may not be predicted accurately.

Table 4. Contributions of positional-entropic energies $\left(T \Delta S_{p}{ }^{0}\right)$ to the reduction potentials in the $F_{n}(n=5$ $10,57)$, and to the lowest triplet free energies in $F_{n}(n=4-10,57)$.

Name \begin{tabular}{cc} 
Anion $\left(\mathrm{F}_{\mathrm{n}}{ }^{-}\right)$ & Triplet $\left({ }^{3} \mathrm{~F}_{\mathrm{n}}{ }^{*}\right)$ \\
\hline${ }^{a} \mathrm{~T} \Delta \mathrm{S}_{\mathrm{p}}{ }^{0}(\mathrm{meV})$ & ${ }^{b} \mathrm{~T} \Delta \mathrm{S}_{\mathrm{p}}{ }^{0}(\mathrm{meV})$
\end{tabular}

$\mathrm{F}_{4}$ 


$\begin{array}{lll}F_{5} & 14 & 28 \\ F_{6} & 26 & 36 \\ F_{7} & 34 & 41 \\ F_{8} & 40 & 46 \\ F_{9} & 45 & 50 \\ F_{10} & 49 & 53 \\ F_{57} & 102 & 103\end{array}$

${ }^{a} \mathrm{~T}=298 \mathrm{~K}$. The $\Delta \mathrm{S}_{\mathrm{p}}{ }^{0}$ is calculated by Equation 1 (see text) with the charge delocalization length $n_{\mathrm{d}}=4.3$ repeat units. $^{9}$

${ }^{b} \mathrm{~T}=298 \mathrm{~K}$. The $\Delta \mathrm{S}_{\mathrm{p}}{ }^{0}$ is calculated by Equation 1 (see text) with the triplet delocalization length $n_{\mathrm{d}}=3.0$ repeat units.

From the dependence of reduction potentials on oligomer length we can obtain information about $n_{\mathrm{d}}$. In Table 4 we see that $\mathrm{T} \Delta \mathrm{S}_{\mathrm{p}}{ }^{0}$ for an increase of the oligomer length by one repeat unit changes $\mathrm{E}^{0}\left(\mathrm{~F}_{\mathrm{n}}{ }^{0 /-}\right)$ by less $12 \mathrm{meV}$, which is about half of $k_{\mathrm{B}} \mathrm{T}(26 \mathrm{meV})$ at $\mathrm{T}=298 \mathrm{~K}$. Therefore when the observed change on adding one unit in $\Delta \mathrm{E}^{0}\left(\mathrm{~F}_{\mathrm{n}}{ }^{0 /-}\right)$ is substantially greater than $12 \mathrm{meV}$, we may conclude that it contains electronic contributions from the energy of the polaron. Conversely when $\Delta E^{0}\left(F_{n}{ }^{0 /-}\right)<12$ meV it is entirely due to positional entropy, and there is no longer a contribution from the $\Delta \mathrm{G}_{\text {calc. }}$. From Table 4 that $\mathrm{E}^{0}\left(\mathrm{~F}_{3}{ }^{0 /-}\right)-\mathrm{E}^{0}\left(\mathrm{~F}_{4}{ }^{0 /-}\right)=-48 \mathrm{meV}$, and $\mathrm{E}^{0}\left(\mathrm{~F}_{5}{ }^{0 /-}\right)-\mathrm{E}^{0}\left(\mathrm{~F}_{4}{ }^{0 /-}\right)=-11 \mathrm{meV}$, these signal that a possible $n_{\mathrm{d}}$ of the electron in the oligofluorene is between 4 and 5 repeat units, consistent with $n_{d}=4.3$ repeat units from the depletion of neutral absorption in $\mathrm{F}_{\mathrm{n}}{ }^{\cdot-}(\mathrm{n}=2-10)$ in $\mathrm{THF}^{9}$

Here eq 1 computes positional entropies under the arbitrary assumption that a change in length of one repeat unit produces a distinct state. If some other value, such a half a repeat unit, is used, the result changes by a small additive factor; while the length-dependence remains almost unchanged. A general procedure to determine the delocalization length from redox potentials or similar data on a series of oligomers is to find the point at which the change of potential upon shortening by one unit is greater than that predicted by eq 1 , in this case $12 \mathrm{meV}$. When $n_{\mathrm{d}}$ is an integral number of repeat units lengthening by $\Delta n_{\mathrm{d}}=1$ gives a change of $18 \mathrm{meV}$, regardless of $n_{\mathrm{d}}$, so once a change of oligomer length by one repeat unit yields a change $>18 \mathrm{meV}$, then the oligomer is shorter than $n_{\mathrm{d}}$.

Chain Entropy vs Empirical Models: Contrasting Predictions. Empirical relationships are frequently

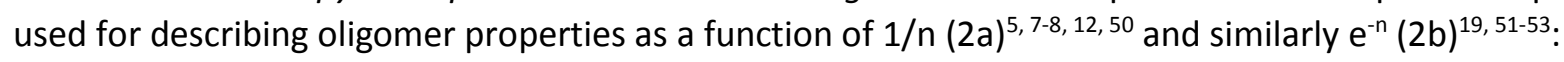

$$
\begin{aligned}
& E_{n}=a+b / n \\
& E_{n}=E_{\infty}+\left(E_{1}-E_{\infty}\right) e^{-a(n-1)}(2 b)
\end{aligned}
$$


They can roughly describe the $\mathrm{E}^{0}\left(\mathrm{~F}_{\mathrm{n}}{ }^{0 /-}\right)$ data as shown in Figure $\mathrm{S} 5$ of the $\mathrm{SI}$, as well as triplet energies discussed below (Fig. S6, SI). The empirical models of eq 2 were developed for short oligomers, so they might not be expected to work well at long lengths where they predict little change. Those predictions are not physically sensible as we can see with a simple example. Here we consider a reaction in which an electron (or hole or exciton) is confined to one molecule, $\mathrm{M}$. Addition of a second $\mathrm{M}$ molecule lets the electron be located on either of the two, decreasing its free energy by $k_{B} \ln (2)=18 \mathrm{meV}$. Now if the molecule, call it $M_{100}$, is a 100 unit long polymer the free energy of the electron in $M_{100}$ decreases by 116 meV due to positional entropy according to eq 1 . For a 200 unit long polymer $M_{200}$ the decrease is by 134 $\mathrm{meV}$, so the free energy change for electron transfer from $\mathrm{M}_{100^{\circ}}{ }^{-2}$ to $\mathrm{M}_{200}$ is $18 \mathrm{meV}$. We would expect that the free energy change for placing the electron on $M_{200}$ would be almost the same as for placing it on two $M_{100}$ molecules. Indeed this is so. The free energy change for placing the electron on two $M_{100}$ molecules is $-\left(116 m e V+k_{B} \ln (2)\right)=-133 \mathrm{meV}$, which is very close to that value, $-134 \mathrm{meV}$ for placing it on $\mathrm{M}_{200}$. The prediction of eq 1 is physically reasonable.

Predictions of the empirical models, eq 2, on the other hand, are not reasonable. Eq 2a predicts differences in polaron free energies for addition of an electron to $M_{100}$ and $M_{200}$ to be far less than $1 \mathrm{meV}$, although it should be close to $18 \mathrm{meV}$. This is true for all values of parameters considered ${ }^{53}$ and is also true for eq $2 \mathrm{a}$. This simple example thus shows that eq 1 makes thermodynamic sense, while eqs $2 \mathrm{a}$ and $2 \mathrm{~b}$ do not.

Triplet Free Energies. Relative $\Delta G^{\circ}$ for of $F_{n}(n=2,4,5,7,10,57)$ were measured from equilibria. The absolute values rely on the free energy change for formation of the triplet state of fluoranthene, based on an analysis of equilibria among triplets of many molecules that obtained free energies. ${ }^{42}$ Therefore reported $\Delta \mathrm{G}^{\circ}$ in the present data are free energy changes for triplet formation. Figure 6a shows that as $n$ increases, the $\Delta G^{\circ}$ of $F_{n}(n=1-3)$ sharply decrease with increasing $n$; the $\Delta G^{\circ}{ }_{T}$ of $F_{n}(n=3-5,7,10)$ decrease more slowly, qualitatively similar to the anions. Computed triplet energies matched well to those from experiment without the shift needed for the anions, so Figure $6 \mathrm{a}$ has just one vertical axis. The repeat-unit-length dependence of the $\Delta \mathrm{G}^{\circ} \mathrm{T}$ based on phosphorescence spectral shifts has been described by using the empirical relationship in eqn. $2 b .^{53}$ Similar fits using empirical functions of current measurements are shown in Figure S6 of the SI. We also estimate $n_{d}$ of the triplet from the $n$ dependence of $\Delta G^{\circ}{ }_{T}\left(F_{n}\right)$ in a way analogous to that used above for anions. In Table 2, the triplet free energy difference between $F_{2}$ and $F_{3}$, $\Delta \Delta G^{\circ}{ }_{T}\left(F_{2}-F_{3}\right)=95 \mathrm{meV}$, is clearly too large to arise solely from positional entropy. $\Delta \Delta G^{\circ}{ }_{T}\left(F_{3}-F_{4}\right)=28$ meV and $\Delta \Delta G_{T}^{\circ}\left(F_{4}-F_{5}\right)=25$ meV both appear too large to be due to positional entropy only, but by an amount close to uncertainty of the measurements. We conclude that the triplet delocalization length is between 3 and 5 repeat units: determination of $n_{d}$ for triplets is unsatisfyingly uncertain. Similarly imprecise determinations have been reported based on comparisons of the length-dependence of spectral shifts between fluorescence and phosphorescence, ${ }^{53}$ as well as computations. ${ }^{52}$ We note that use of spectral shifts does not capture free energies due to positional entropy. While the picture introduced here describes the observations well in terms of a rigid polaron of fixed length, this simple picture is not exact. 
Dihedral angles fluctuate thermally, producing fluctuations in polaron lengths for both anions and triplets: polarons "breathe" as dihedrals fluctuate. The vague determination of the delocalization length for triplets may signal that the triplet spreads and contracts by large amounts as dihedral angles undergo thermal fluctuations, producing fluctuation in the length of the triplet. The average length of the triplet may near three repeat units, but may fluctuate to lengths greater than four units because the triplet length is more sensitive to dihedral angles than is the anion. This hypothesis is supported by the finding, first reported by Jansson ${ }^{52}$ that optimized structures of triplets contain one dihedral angle close to zero. A similar analysis is presented in Figure S7.

Triplet absorption (TA) spectra in Figure 2, on the other hand, continue to change with $n$ until at least $n=6$. This observation does not conflict with the idea that the triplet delocalization length is near 3 repeat units, as noted by Jansson ${ }^{52}$ and coworkers, who found similar changes in computed TA spectra, ${ }^{52}$ consistent with experimental determinations by Wasserberg in $80 \mathrm{~K}$ MTHF glasses. ${ }^{53}$ The positions of the TA bands are determined by differences between the energies of triplet ground and excited states ( $T_{1}$ and $\left.T_{n}\right)$. The data in Figure 2 thus show that the delocalization length of the $T_{n}$ state is at least $n=6$, but the delocalization length of the $T_{1}$ state could be much shorter. Determination of delocalization length for the lowest, $T_{1}$, state should be based on properties of this state, as are the energies in Figure 4.

Still, as for the anions the dependence on $n$ for the triplets is also described well by the sum of the $\Delta \mathrm{G}_{\text {calc }}$ and $\mathrm{T} \Delta \mathrm{S}_{\mathrm{p}}{ }^{0}$ in Figure 6a. Here, $\Delta \mathrm{S}_{\mathrm{p}}{ }^{0}$ is calculated by eq. 1 with $n_{\mathrm{d}}=3.0$ repeat units; $T \Delta \mathrm{S}_{\mathrm{p}}{ }^{0}$ in the $\Delta G^{\circ}{ }_{T}$ of $F_{n}(n=4-10,57)$ are given in Table 4. Figure $6 \mathrm{~b}$ shows the plots of the $\Delta G_{\text {calc }}$ and $T \Delta S_{p}{ }^{0}$ versus $n$. As for anions, $\Delta S_{p}^{0}$ is zero for $n<n_{d}$. 

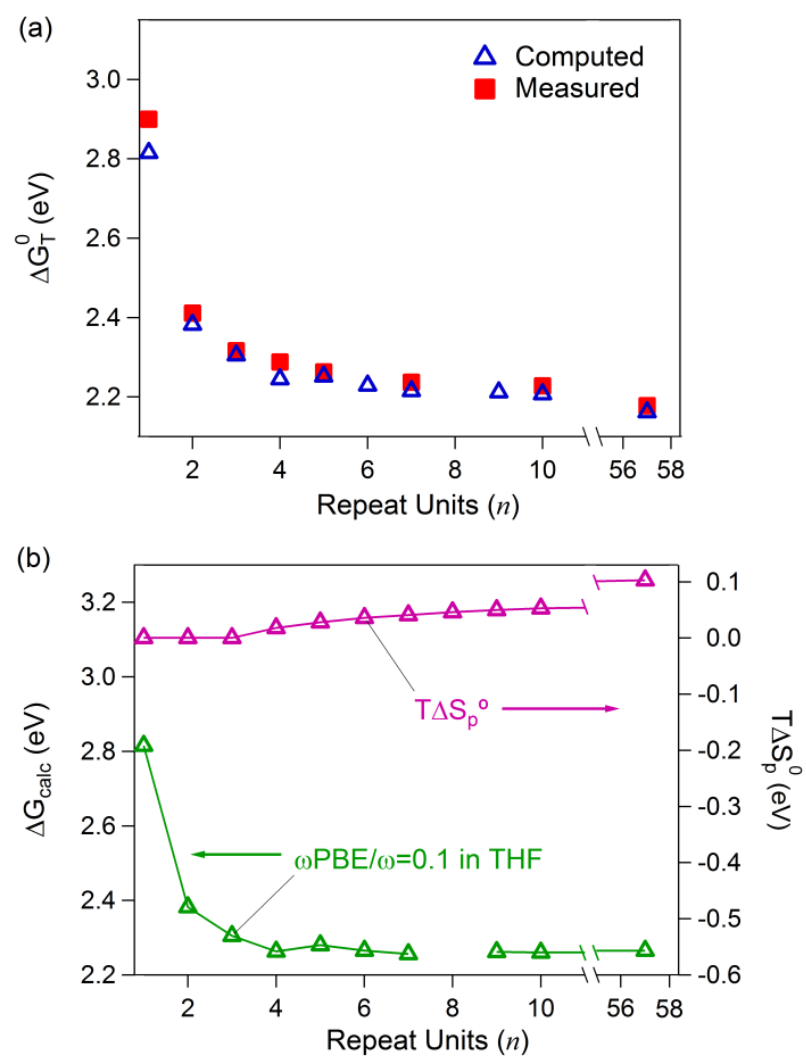

Figure 6. Free energies changes $\left(\Delta \mathrm{G}^{\circ} \mathrm{T}\right)$ vs. oligomer or polymer length $n$ for formation of triplets from ground states: (a) measured (red) and computed (blue), $\Delta \mathrm{G}^{\circ} \mathrm{T}$, for $\mathrm{F}_{\mathrm{n}}(\mathrm{n}=1-7,9,10,57)$; (b) the computed triplet free energy $\left(\Delta \mathrm{G}_{\text {calc }}\right.$, green) and positional-entropic energy $\left(T \Delta S_{p}{ }^{0} ; T=298 \mathrm{~K}\right.$, purple) of $F_{n}(n=1-10)$ vs. $n$. The computed $\Delta G^{\circ}{ }_{T}$ is $\Delta G_{\text {calc }}-T \Delta S_{p}{ }^{0}$ eV. $\Delta S_{p}{ }^{0}$ is from eq 1 with the triplet delocalization length $n_{d}=3.0$ repeat units. The $\Delta S_{p}{ }^{0}$ of $F_{n}(n=1-3)$ are assumed to be zero (see text).

Rate Constants for Electron and Triplet Transfer. Rate constants for bimolecular triplet transfer usually utilized $\mathrm{F}_{3}$ due to its strong, but distinct spectrum. Except for transfer to $\mathrm{pF}_{57}$ these rate constants were all below $1 \times 10^{9} \mathrm{M}^{-1} \mathrm{~s}^{-1}$. For example triplet transfer from ${ }^{3} \mathrm{~F}_{3}{ }^{*}$ to $\mathrm{F}_{10}$, with $\Delta \mathrm{G}^{0}=88 \mathrm{meV}$ proceeded with a rate constant of $4.1 \times 10^{8} \mathrm{M}^{-1} \mathrm{~s}^{-1}$. By contrast several rate constants for electron transfer were $>1 \times 10^{10} \mathrm{M}^{-}$ ${ }^{1} \mathrm{~s}^{-1}$. The slow rates for triplet transfer are remarkable. They may arise because electronic coupling for triplet excitation transfer is smaller than that for electron transfer or because reorganization energies are larger for triplet transfer. One source of reorganization energy is the large change in one dihedral angle noted in Figure S7 of the SI.

\section{Summary and Recommendations}

For oligofluorenes with repeat unit lengths $(n)$ less than the delocalization length, $n_{\mathrm{d}}, \Delta \mathrm{G}^{0}$ for forming anions or triplets decreases rapidly with increasing $n$. For $n>n_{\mathrm{d}}$, the observed free 
energy change decreases much more slowly in a way similar earlier reports of length dependence in varied oligomers. The present paper describes a definite origin for the changing free energies in longer oligomers and polymers. The changes with length are in accord with a picture in which for $n>n_{\mathrm{d}}$ the energy of the electron or triplet polaron is constant, but "positional entropy" arising from different positions of the electron or triplet polaron in the chain slowly decreases the free energy change. A smaller internal entropy change also accompanies the creation of each polaron. A simple picture of the length-dependences accounts for the experimental measurements and is an alternative to widely-used empirical relations. ${ }^{51} 51$ The delocalization length of the electron polaron is 4-5 repeat units in agreement with previous reports. ${ }^{9}$ There is some ambiguity about the length of the triplet exciton which lies between 3 and 5 repeat units. This simple picture, which includes an electron or triplet polaron of fixed length, is readily expressed in a quantitative model. While it is oversimplified because it does not include fluctuations of polaron length, it works well enough that departures from it are close to experimental uncertainties. The predictions of long-range corrected $\omega \mathrm{PBE}$ computations on electrons and triplet oligofluorenes are in accord with this length range. The polaron delocalization lengths found here use the redox potential, a ground state property, or the energy of the lowest triplet to obtain lengths of the polarons in their lowest electronic states. These lengths are consistent with previous reports.

Positional entropy explains the chemical physics behind the evolution of free energy changes past the delocalization length for conjugated polymers. Such insight is missing and possibly misleading in empirical $1 / n$ or $\mathrm{e}^{-\mathrm{n}}$ descriptions commonly employed for spectral and energetic data. Positional entropies can be substantial, $>100$ meV for example for $F_{57}$, as shown in Table 4, or 158 meV for a 500 unit polymer. When measurements on a series of oligomers are available the positional entropy also provides a new and more rigorous method compared to inspecting plots vs $1 / \mathrm{n}$ to determine delocalization lengths for polarons. A general procedure to determine the delocalization length from redox potentials or similar data on a series of oligomers is to find the point at which the change of potential upon shortening by one unit is greater than that predicted by eq 1 . This change is $12 \mathrm{meV}$ or somewhat smaller if $n_{\mathrm{d}}$ is not an integer. The empirical descriptions, eqs 2 have no clear meaning, but provide good descriptions for oligomers having lengths less than $\mathrm{n}_{\mathrm{D}}$.

Acknowledgement We gratefully acknowledge the support of the Division of Chemical Sciences, Geosciences, and Biosciences through Grant DE-AC02-98-CH10886, including use of the LEAF facility of the BNL Accelerator Center for Energy Research.

\section{Supporting Information}

The Supporting Information is available free of charge on the ACS Publications website at DOI:

1. Radiation Chemistry in THF, toulene, and $p$-xylene.

2. Tables for computed electronic energies with the symmetry constraints for forming the triplets, and the computed free energies, enthalpies, and entropies without symmetry constraints for forming the anions and triplets. 
3. Figures showing spectral evolution between triplets from which $\Delta G_{T}^{\circ}$ is determined, comparison of $F_{n}$ oxidation and reduction potentials with empirical fits, and a plot showing the commonly used empirical $1 / \mathrm{n}$ relationship for triplet energy with oligomer length.

4. Computed dihedral angles for triplet oligomers $F_{n}, n=3-7,10$.

\section{Acknowledgment}

This work, and use of the LEAF facility of the BNL Accelerator Center for Energy Research, was supported by the U.S. Department of Energy, Office of Science, Office of Basic Energy Sciences, Division of Chemical Sciences, Geosciences \& Biosciences, under Contract No. DE-SC0012704.

\section{References}

1. Song, H.; Reed, M. A.; Lee, T. Single Molecule Electronic Devices. Adv. Mater. 2011, 23, 1583-1608.

2. Born, M. Volumen Und Hydratationswärme Der Ionen. Zeitschrift für Physik 1920, 1, 4548.

3. Kulkarni, A. P.; Tonzola, C. J.; Babel, A.; Jenekhe, S. A. Electron Transport Materials for Organic Light-Emitting Diodes. Chem. Mater. 2004, 16, 4556-4573.

4. Günes, S.; Neugebauer, H.; Sariciftci, N. S. Conjugated Polymer-Based Organic Solar Cells. Chem. Rev. 2007, 107, 1324-1338.

5. Bredas, J. L.; Silbey, R.; Boudreaux, D. S.; Chance, R. R. Chain-Length Dependence of Electronic and Electrochemical Properties of Conjugated Systems: Polyacetylene, Polyphenylene, Polythiophene, and Polypyrrole. J. Am. Chem. Soc. 1983, 105, 6555-6559.

6. Brédas, J.-L.; Beljonne, D.; Coropceanu, V.; Cornil, J. Charge-Transfer and EnergyTransfer Processes in П-Conjugated Oligomers and Polymers: A Molecular Picture. Chem. Rev. 2004, 104, 4971-5004.

7. Chi, C.; Wegner, G. Chain-Length Dependence of the Electrochemical Properties of Conjugated Oligofluorenes. Macromol. Rapid Commun. 2005, 26, 1532-1537.

8. Guay, J.; Kasai, P.; Diaz, A.; Wu, R.; Tour, J. M.; Dao, L. H. Chain-Length Dependence of Electrochemical and Electronic Properties of Neutral and Oxidized Soluble $\alpha, \alpha$-Coupled Thiophene Oligomers. Chem. Mater. 1992, 4, 1097-1105.

9. Zaikowski, L.; Kaur, P.; Gelfond, C.; Selvaggio, E.; Asaoka, S.; Wu, Q.; Chen, H.-C.; Takeda, N.; Cook, A. R.; Yang, A., et al. Polarons, Bipolarons, and Side-by-Side Polarons in Reduction of Oligofluorenes. J. Am. Chem. Soc. 2012, 134, 10852-10863.

10. Takeda, N.; Asaoka, S.; Miller, J. R. Nature and Energies of Electrons and Holes in a Conjugated Polymer, Polyfluorene. J. Am. Chem. Soc. 2006, 128, 16073-16082.

11. Takeda, N.; Miller, J. R. Poly(3-Decylthiophene) Radical Anions and Cations in Solution: Single and Multiple Polarons and Their Delocalization Lengths in Conjugated Polymers. J. Phys. Chem. B 2012, 116, 14715-14723.

12. Elandaloussi, E. H.; Frère, P.; Richomme, P.; Orduna, J.; Garin, J.; Roncali, J. Effect of Chain Extension on the Electrochemical and Electronic Properties of П-Conjugated Soluble Thienylenevinylene Oligomers. J. Am. Chem. Soc. 1997, 119, 10774-10784. 
13. Monkman, A. P.; Burrows, H. D.; Hartwell, L. J.; Horsburgh, L. E.; Hamblett, I.; Navaratnam, S. Triplet Energies of П-Conjugated Polymers. Phys. Rev. Lett. 2001, 86, 1358-1361. 14. Monkman, A. P.; Burrows, H. D.; Miguel, M. d. G.; Hamblett, I.; Navaratnam, S. Triplet State Spectroscopy of Conjugated Polymers Studied by Pulse Radiolysis. Synth. Met. 2001, 116, 75-79.

15. Beljonne, D.; Ye, A.; Shuai, Z.; Brédas, J. L. Chain-Length Dependence of Singlet and Triplet Exciton Formation Rates in Organic Light-Emitting Diodes. Adv. Funct. Mater. 2004, 14, 684-692.

16. Köhler, A.; Beljonne, D. The Singlet-Triplet Exchange Energy in Conjugated Polymers. Adv. Funct. Mater. 2004, 14, 11-18.

17. Chi, C.; Im, C.; Wegner, G. Lifetime Determination of Fluorescence and Phosphorescence of a Series of Oligofluorenes. J. Chem. Phys. 2006, 124, 024907(1-8).

18. Beljonne, D.; Cornil, J.; Friend, R. H.; Janssen, R. A. J.; Brédas, J. L. Influence of Chain Length and Derivatization on the Lowest Singlet and Triplet States and Intersystem Crossing in Oligothiophenes. J. Am. Chem. Soc. 1996, 118, 6453-6461.

19. Rissler, J. Effective Conjugation Length of Pi-Conjugated Systems. Chem. Phys. Lett. 2004, 395, 92-96.

20. Gregg, B. A. Entropy of Charge Separation in Organic Photovoltaic Cells: The Benefit of Higher Dimensionality. J. Phys. Chem. Lett. 2011, 2, 3013-3015.

21. Clarke, T. M.; Durrant, J. R. Charge Photogeneration in Organic Solar Cells. Chem. Rev. 2010, 110, 6736-6767.

22. Hood, S. N.; Kassal, I. Entropy and Disorder Enable Charge Separation in Organic Solar Cells. J. Phys. Chem. Lett. 2016, 4495-4500.

23. Sreearunothai, P.; Asaoka, S.; Cook, A. R.; Miller, J. R. Length and Time-Dependent Rates in Diffusion-Controlled Reactions with Conjugated Polymers. J. Phys. Chem. A 2009, 113, 27862795.

24. Wishart, J. F.; Cook, A. R.; Miller, J. R. The Leaf Picosecond Pulse Radiolysis Facility at Brookhaven National Laboratory. Rev. Sci. Instrum. 2004, 75, 4359-4366.

25. Onsager, L. Initial Recombination of Ions. Physical Review 1938, 54, 554.

26. Tran-Thi, T. H.; Koulkes-Pujo, A. M. Electron and Organic Radical Anion Solvation. Pulse Radiolysis of Tetrahydrofuran and Its Solutions of N-Methylacetamide or Pyrrolidone. J. Phys. Chem. 1983, 87, 1166-1169.

27. Pedersen, S. U.; Bo Christensen, T.; Thomasen, T.; Daasbjerg, K. New Methods for the Accurate Determination of Extinction and Diffusion Coefficients of Aromatic and Heteroaromatic Radical Anions in N,N-Dimethylformamide. J. Electroanal. Chem. 1998, 454, 123-143.

28. Shida, T., Electronic Absorption Spectra of Radical Ions; Elsevier Science, 1998.

29. Carmichael, I.; Hug, G. L. Triplet-Triplet Absorption-Spectra of Organic-Molecules in Condensed Phases. J. Phys. Chem. Ref. Data 1986, 15, 1-250.

30. Carmichael, I.; Helman, W. P.; Hug, G. L. Extinction Coefficients of Triplet-Triplet Absorption-Spectra of Organic-Molecules in Condensed Phases - a Least-Squares Analysis. $J$. Phys. Chem. Ref. Data 1987, 16, 239-260.

31. Sreearunothai, P.; Estrada, A.; Asaoka, S.; Kowalczyk, M.; Jang, S.; Cook, A. R.; Preses, J. M.; Miller, J. R. Triplet Transport to and Trapping by Acceptor End Groups on Conjugated Polyfluorene Chains. J. Phys. Chem. C 2011, 115, 19569-19577.

32. Saltiel, J.; Khalil, G.-E.; Schanze, K. Trans-Stilbene Phosphorescence. Chem. Phys. Lett. 1980, 70, 233-235. 
33. Saltiel, J.; Thomas, B. Nonvertical Deactivation and Lifetime and Geometry of Stilbene Triplets in Solution. J. Am. Chem. Soc. 1974, 96, 5660-5661.

34. Meerholz, K.; Heinze, J. Multiple Reversible Electrochemical Reduction of Aromatic Hydrocarbons in Liquid Alkylamines. J. Am. Chem. Soc. 1989, 111, 2325-2326.

35. Shalev, H.; Evans, D. H. Solvation of Anion Radicals: Gas-Phase Versus Solution. J. Am. Chem. Soc. 1989, 111, 2667-2674.

36. Bensasson, R.; Land, E. J. Triplet-Triplet Extinction Coefficients Via Energy Transfer. Trans. Faraday Soc. 1971, 67, 1904-14.

37. Heinzelmann, W.; Labhart, H. Triplet-Triplet Spectra and Triplet Quantum Yields of Some Aromatic Hydrocarbons in Liquid Solution. Chem. Phys. Lett. 1969, 4, 20-24.

38. Wagner, P. J. Conformational Changes Involved in the Singlet-Triplet Transitions of Biphenyl. J. Am. Chem. Soc. 1967, 89, 2820-2825.

39. Amand, B.; Bensasson, R. Determination of Triplet Quantum Yields by Laser Flash Absorption Spectroscopy. Chem. Phys. Lett. 1975, 34, 44-48.

40. Hoffman, M. Z.; Porter, G. Radiationless Conversion from the Triplet State. Proc. R. Soc. London, A 1962, 268, 46-56.

41. Kuzmin, V. A.; Tatikolov, A. S. Energy Transfer in the Course of Triplet State Quenching of Aromatic Hydrocarbons by Nitroxyl Radicals. Chem. Phys. Lett. 1978, 53, 606-610.

42. Merkel, P. B.; Dinnocenzo, J. P. Thermodynamic Energies of Donor and Acceptor Triplet States. J. Photochem. Photobiol., A 2008, 193, 110-121.

43. Marenich, A. V.; Cramer, C. J.; Truhlar, D. G. Universal Solvation Model Based on Solute Electron Density and on a Continuum Model of the Solvent Defined by the Bulk Dielectric Constant and Atomic Surface Tensions. J. Phys. Chem. B 2009, 113, 6378-6396.

44. $\quad$ Frisch, M. J.; Trucks, G. W.; Schlegel, H. B.; Scuseria, G. E.; Robb, M. A.; Cheeseman, J. R.; Scalmani, G.; Barone, V.; Mennucci, B.; Petersson, G. A., et al. Gaussian 09, Revision D.01; Gaussian Inc.: Wallingford, CT, 2009.

45. Kaufman, J. H.; Chung, T. C.; Heeger, A. J. Fundamental Electrochemical Studies of Polyacetylene. J. Electrochem. Soc. 1984, 131, 2847-2856.

46. Connelly, N. G.; Geiger, W. E. Chemical Redox Agents for Organometallic Chemistry. Chem. Rev. 1996, 96, 877-910.

47. Chang, D.; Malinski, T.; Ulman, A.; Kadish, K. M. Electrochemistry of Nickel(Ii) Porphyrins and Chlorins. Inorg. Chem. 1984, 23, 817-824.

48. Bard, A. J.; Faulkner, L. R., Electrochemical Methods: Fundamentals and Applications, 2 nd ed.; John Wiley \& Sons, 2001, p 864.

49. Ratkova, E. L.; Palmer, D. S.; Fedorov, M. V. Solvation Thermodynamics of Organic Molecules by the Molecular Integral Equation Theory: Approaching Chemical Accuracy. Chem. Rev. 2015, 115, 6312-6356.

50. Klaerner, G.; Miller, R. D. Polyfluorene Derivatives: Effective Conjugation Lengths from Well-Defined Oligomers. Macromolecules 1998, 31, 2007-2009.

51. Meier, H.; Stalmach, U.; Kolshorn, H. Effective Conjugation Length and Uv/Vis Spectra of Oligomers. Acta Polym. 1997, 48, 379-384.

52. Jansson, E.; Jha, P. C.; Ågren, H. Chain Length Dependence of Singlet and Triplet Excited States of Oligofluorenes: A Density Functional Study. Chem. Phys. 2007, 336, 91-98.

53. Wasserberg, D.; Dudek, S. P.; Meskers, S. C. J.; Janssen, R. A. J. Comparison of the Chain Length Dependence of the Singlet- and Triplet-Excited States of Oligofluorenes. Chem. Phys. Lett. 2005, 411, 273-277. 
TOC Graphic

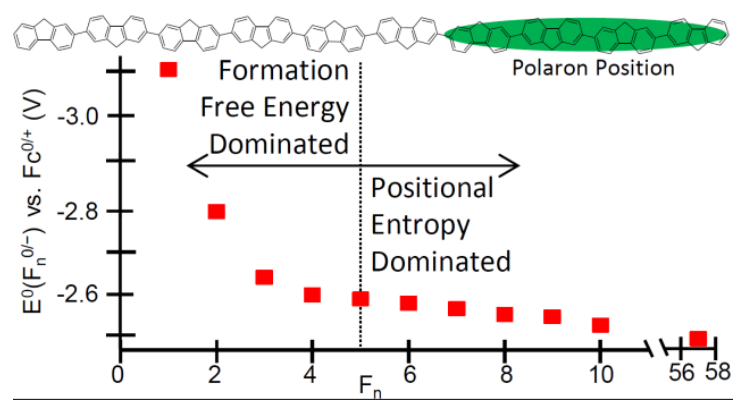


Supporting Information For:

\section{Chain Length Dependence of Energies of Electron}

\section{and Triplet Polarons in Oligofluorenes}

Hung Cheng Chen ${ }^{\dagger}$, Paiboon Sreearunothai ${ }^{\ddagger}$, Andrew R. Cook ${ }^{\dagger}$, Sadayuki Asaoka ${ }^{\perp}$, Qin Wu ${ }^{\S}$, John R. Miller $^{*+}$

${ }^{\dagger}$ Chemistry Department and ${ }^{\S}$ Center of Functional Nanomaterials, Brookhaven National Laboratory, Upton, NY 11973

${ }^{\ddagger}$ Sirindhorn International Institute of Technology, Thammasat University - Pathum Thani 12121, Thailand

${ }^{\perp}$ Faculty of Materials Science and Engineering, Kyoto Institute of Technology, Matsugasaki, Sakyo-ku, Kyoto 606-8585, Japan 


\section{Section S1: Radiation Chemistry for making anions and triplets}

Anions in Tetrahydrofuran (THF) With the concentration of the donor (D) much greater than that of the acceptor (A), the radiation chemistry in $\mathrm{THF}(=\mathrm{RH})$ solution are:

$$
\begin{array}{ll}
\mathrm{RH} \stackrel{\text { Electron Pulse }}{\longrightarrow} \mathrm{RH}^{\bullet+}+\mathrm{e}_{\mathrm{s}}^{-} & \text {(Ionization) } \\
\mathrm{RH}^{\bullet+}+\mathrm{RH} \rightarrow \mathrm{RH}_{2}^{+}+\mathrm{R}^{\bullet} & \text { (Formation of Solvated Proton) } \\
\mathrm{D}+\mathrm{e}_{\mathrm{s}}^{-} \rightarrow \mathrm{D}^{\bullet-} & \text { (Electron Attachment) } \\
\mathrm{A}+\mathrm{e}_{\mathrm{s}}^{-} \rightarrow \mathrm{A}^{\bullet-} & \text { (Electron Transfer) } \\
\mathrm{D}^{\bullet-}+\mathrm{A} \leftrightarrow \mathrm{D}+\mathrm{A}^{\bullet-} & \text { (Proton Transfer) } \\
\mathrm{D}^{\bullet-}+\mathrm{RH}_{2}^{+} \rightarrow \mathrm{DH}^{\bullet}+\mathrm{RH} & \\
\mathrm{A}^{\bullet-}+\mathrm{RH}_{2}^{+} \rightarrow \mathrm{AH}^{\bullet}+\mathrm{RH} &
\end{array}
$$

where $\mathrm{RH}_{2}^{+}$is the solvated proton and $\mathrm{e}_{\mathrm{s}}^{-}$is the solvated electron. The formation of the solvated protons are fast $(<1 \mathrm{ps}),{ }^{1}$ so very little solute will be oxidized by $\mathrm{RH}^{\circ+}$. Reaction $\mathrm{R} 4$ involves encounters of $\mathrm{D}^{*-}$ with $\mathrm{A}$ and reaction and the reverse, which are not dependent on reactions of R5a and R5b so once decay due to R5a and R5b is accounted for, equilibria can be determined independently. Because of [D] $>[\mathrm{A}]$, most solvated electrons will kinetically attach to the $\mathrm{D}$ and then the electrons transfer (ET) to A (Reaction R4). In THF, the anions are annihilated by the proton transfer reaction (Reaction R5).

Triplets in Toluene and $p$-Xylene In aromatic solvents (Ar) such as toluene and $p$-xylene with that the concentration of the donor (D) greater than that of the acceptor (A), the radiation chemistry is:

$$
\begin{array}{ll}
\mathrm{Ar} \stackrel{\text { electron pulse }}{\longrightarrow}{ }^{1} \mathrm{Ar}^{*} \text { and }{ }^{3} \mathrm{Ar}^{*} & \text { (Excitation) } \\
\mathrm{Ar} \stackrel{\text { electron pulse }}{\longrightarrow} \mathrm{e}_{\mathrm{s}}^{-}+\mathrm{Ar}^{\bullet+} & \text { (Ionization) } \\
\mathrm{Ar}+\mathrm{e}_{\mathrm{s}}^{-} \rightarrow \mathrm{Ar}^{\bullet-} & \\
\mathrm{Ar}^{\bullet-}+\mathrm{Ar}^{\bullet+} \rightarrow \mathrm{Ar}+{ }^{1} \mathrm{Ar}^{*} \mathrm{or}{ }^{3} \mathrm{Ar}^{*} & \text { (Charge Recombination) } \\
{ }^{1} \mathrm{Ar}^{*} \rightarrow{ }^{3} \mathrm{Ar}^{*} & \text { (Intersystem Crossing) } \\
{ }^{3} \mathrm{Ar}^{*}+\mathrm{D} \rightarrow \mathrm{Ar}+{ }^{3} \mathrm{D}^{*} & \text { (Triplet State Forming) }
\end{array}
$$




$$
{ }^{3} \mathrm{D}^{*}+\mathrm{A} \leftrightarrow \mathrm{D}+{ }^{3} \mathrm{~A}^{*} \quad \text { (Triplet Excitation Transfer) }
$$

Here ${ }^{1} \mathrm{Ar}^{*}$ and ${ }^{3} \mathrm{Ar}^{*}$ are the singlet and triplet excited solvent molecules; ${ }^{3} \mathrm{~A}^{*}$ and ${ }^{3} \mathrm{D}^{*}$ are the triplet excited states of $\mathrm{A}$ and $\mathrm{D}$. The electron pulse can excite Ar directly to form ${ }^{1} \mathrm{Ar}^{*}$ and ${ }^{3} \mathrm{Ar}^{*}$. The ionization of the solvent is rapidly ( $<2 \mathrm{~ns}$ ) followed by charge recombination (Reaction S8) that leads to ${ }^{1} \mathrm{Ar}^{*}$ and ${ }^{3} \mathrm{Ar}^{*}$. The ${ }^{1} \mathrm{Ar}^{*}$ convert into ${ }^{3} \mathrm{Ar}^{*}$ via the intersystem crossing (Reaction S9). Due to the concentration gradient [D] > [A], the D will capture the triplet energy first (Reaction $\mathrm{R} 10$ ) and then the triplet energy will transfer to A (Reaction R11). 
Table S2: Computed electronic formation energies for $\mathbf{F}_{\mathbf{n}} \mathbf{( n = 1 - 1 0 )}$ triplets by long-range corrected $\omega \mathrm{PBE} / 3-21 \mathrm{G}\left(\omega=0.07 \mathrm{bohr}^{-1}\right)$ with the symmetry constraints, and the PCM solvation model for THF. These energies are the computed electronic energy differences between the ground and lowest triplet excited states.

\begin{tabular}{|c|c|}
\hline Name & Triplets \\
\hline$F_{1}$ & 3.09876 \\
\hline$F_{2}$ & 2.60391 \\
\hline$F_{3}$ & 2.58195 \\
\hline$F_{4}$ & 2.53106 \\
\hline$F_{5}$ & 2.56752 \\
\hline$F_{6}$ & 2.52923 \\
\hline$F_{7}$ & 2.56716 \\
\hline$F_{8}$ & 2.52885 \\
\hline$F_{9}$ & 2.56755 \\
\hline$F_{10}$ & 2.52815 \\
\hline
\end{tabular}

Table S3 Computed free energies $\left(\Delta \mathrm{G}^{0}\right)$, enthalpies $\left(\Delta \mathrm{H}^{0}\right)$, and vibration-entropic energies $\left(\mathbf{T} \Delta \mathbf{S}_{\mathbf{v i b}} ; \mathbf{T}=\mathbf{2 9 8} \mathbf{K}\right)$ for forming $F_{n}(n=1-8,10)$ anions, and $F_{n}(n=1-7,10)$ triplets by long-range corrected $\omega \mathrm{PBE} / 6-31 \mathrm{G}(\mathrm{d})\left(\omega=0.1 \mathrm{bohr}^{-1}\right)$ with the SMD solvation model in THF, and without the symmetry constraints. These contributions are internal to the polarons and do NOT include the larger contributions from positional entropies.

\begin{tabular}{|c|c|c|c|c|c|c|}
\hline & \multicolumn{3}{|c|}{${ }^{a}$ Anions } & \multicolumn{3}{c|}{${ }^{b}$ Triplets } \\
\cline { 2 - 7 } & $\Delta \mathrm{G}^{0}(\mathrm{eV})$ & $\Delta \mathrm{H}^{0}(\mathrm{eV})$ & $\mathrm{T} \Delta \mathrm{S}_{\text {vib }}(\mathrm{eV})$ & $\Delta \mathrm{G}^{0}(\mathrm{eV})$ & $\Delta \mathrm{H}^{0}(\mathrm{eV})$ & $\mathrm{T} \Delta \mathrm{S}_{\text {vib }}(\mathrm{eV})$ \\
\hline $\mathrm{F}_{1}$ & -1.187 & -1.135 & 0.033 & 2.815 & 2.897 & 0.057 \\
\hline $\mathrm{F}_{2}$ & -1.680 & -1.622 & 0.058 & 2.382 & 2.439 & 0.028 \\
\hline $\mathrm{F}_{3}$ & -1.784 & -1.733 & 0.038 & 2.305 & 2.374 & 0.042 \\
\hline $\mathrm{F}_{4}$ & -1.816 & -1.778 & 0.022 & 2.258 & 2.345 & 0.057 \\
\hline $\mathrm{F}_{5}$ & -1.852 & -1.787 & 0.047 & 2.262 & 2.361 & 0.071 \\
\hline $\mathrm{F}_{6}$ & -1.802 & -1.787 & -0.003 & 2.273 & 2.347 & 0.056 \\
\hline $\mathrm{F}_{7}$ & -1.877 & -1.794 & 0.064 & 2.257 & 2.338 & 0.053 \\
\hline $\mathrm{F}_{8}$ & -1.842 & -1.801 & 0.041 & & & \\
\hline $\mathrm{F}_{9}$ & & & & 2.233 & 2.336 & 0.075 \\
\hline $\mathrm{F}_{10}$ & -1.829 & -1.796 & -0.002 & 2.252 & 2.341 & 0.048 \\
\hline
\end{tabular}

${ }^{a}$ For forming the anions at $\mathrm{T}=298 \mathrm{~K}$, the electron-entropic energies are $18 \mathrm{meV}$, and both the rotation and translation entropic energies are $\sim 1 \mathrm{meV}$.

${ }^{b}$ For forming the triplets at $\mathrm{T}=298 \mathrm{~K}$, the electron-entropic energies are $28 \mathrm{meV}$, and both the rotation and translation entropic energies are $\sim 1 \mathrm{meV}$. 
Figure S4. Spectral evolution showing triplet transfer between $F_{3}$ and $F_{5}$. Figure In toluene with $40 \mathrm{mM}$ of naphthalene, triplet spectra from pulse radiolysis of a mixture sample of $F_{3}$ and $F_{5}$. As time goes by, the $F_{3}$ triplets gradually transfer to $F_{5}$ to reach equilibria, allowing determination of $\Delta G^{\circ}$ from $K_{\text {eq。 }}$

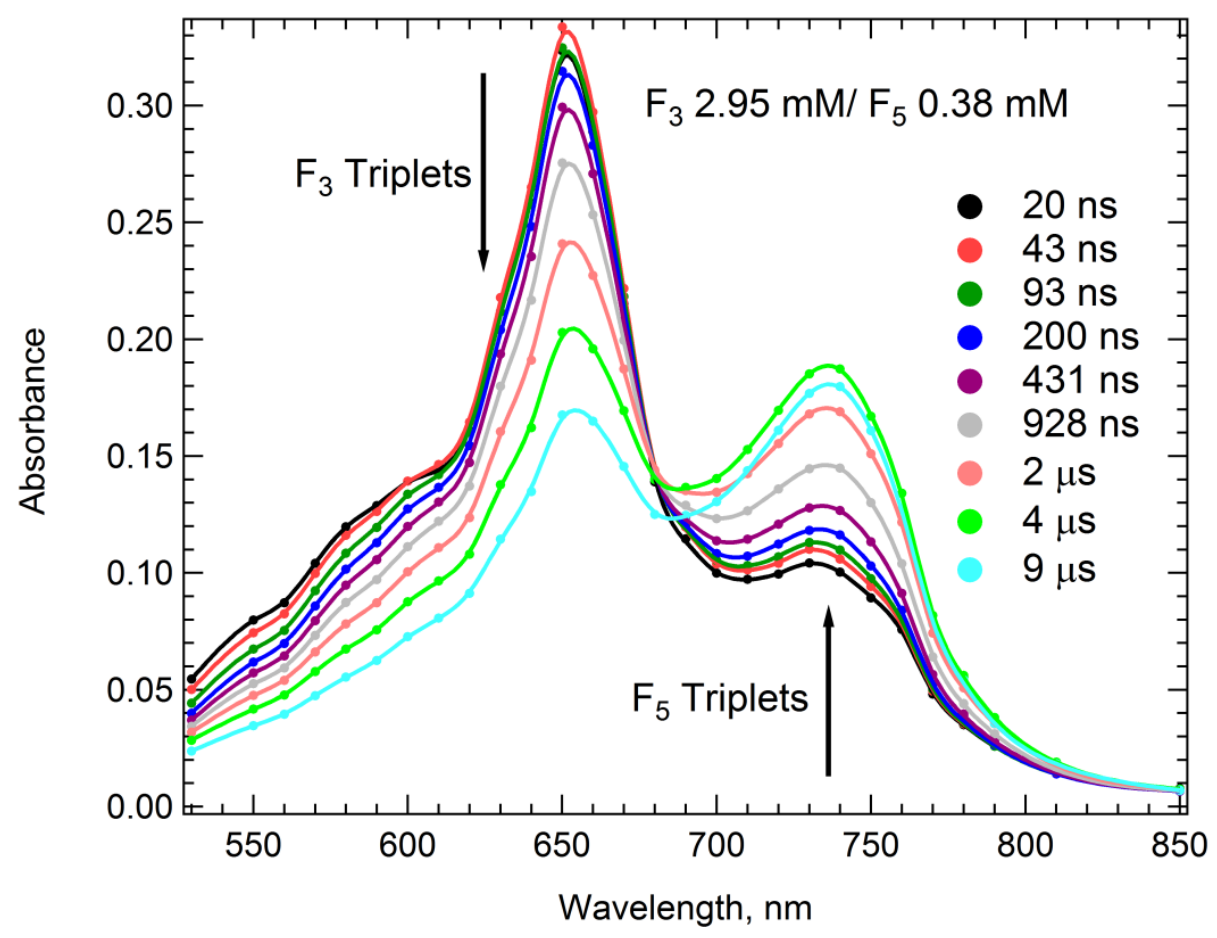


Figure S5. A plot of the reduction potentials of $F_{n}(n=1-10,57)$ vs. the length in the repeat units (data from Figure 5) compared with the empirical functions Eq 2a (blue line) and 2b (green line). These empirical functions for the oligomers are fair, but not as good as the description based on positional entropy given in the main manuscript. Eq 2a is almost as good but eq $2 \mathrm{~b}$ fails to predict the substantial change for $\mathrm{pF}_{57}$. The empirical fits are $\mathrm{E}^{0}\left(\mathrm{~F}_{\mathrm{n}}{ }^{0 /-}\right)=-2.46-0.65(1 / n)$ (Eq. 2a, blue line), and $\mathrm{E}^{0}\left(\mathrm{~F}_{\mathrm{n}}{ }^{0 /}\right)=-2.256-(-3.098+2.256) \exp [-0.693(n-1)]$ (Eq. 2b, green line).

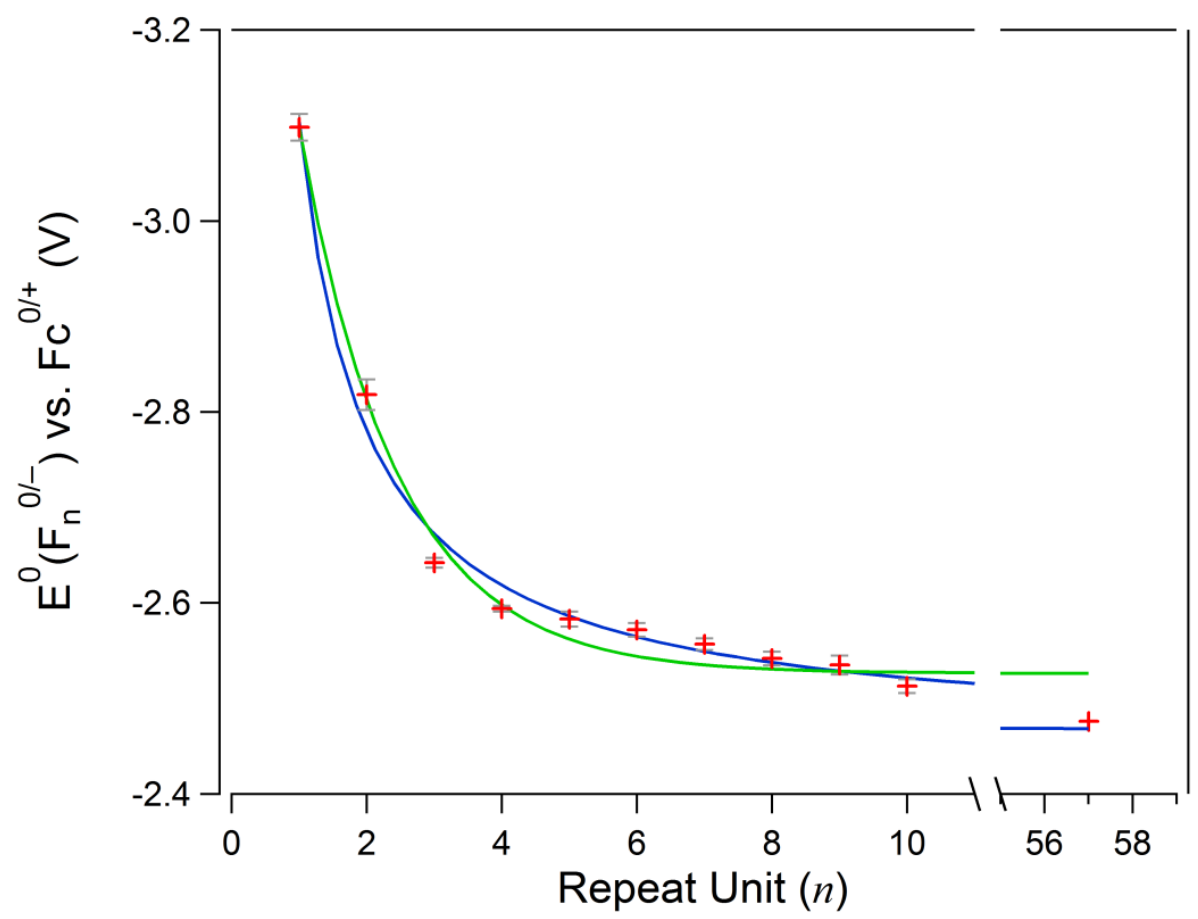


Figure S6. The lowest triplet energy $\left(\Delta G^{0}{ }_{T}\right)$ of $F_{n}(n=2-5,7,10,57)$ vs. the length in the repeat units ( $n$ ) (data from Figure 6) compared with Eq. 2.; $\Delta \mathrm{G}_{\mathrm{T}}{ }^{0}=2.12+0.73(1 / n) \mathrm{eV}$ (Eq. 2a, blue line), and $\Delta \mathrm{G}_{\mathrm{T}}{ }^{0}=2.234+(2.9-2.234) \exp [-1.191(n-1)] \mathrm{eV}$ (Eq. 2b, green line). The parameter $2.9 \mathrm{eV}$ is the reported triplet energy of $F_{1}$. The other two parameters were adjusted for best fit. Eq $2 \mathrm{a}$ can approximately describe the length dependence, but is slightly inferior to that given by the positional entropy model seen in figure 6 . Again $\mathrm{Eq} 2 \mathrm{~b}$ fails to predict the noticeable change between $\mathrm{F}_{10}$ and $\mathrm{pF}_{57}$.

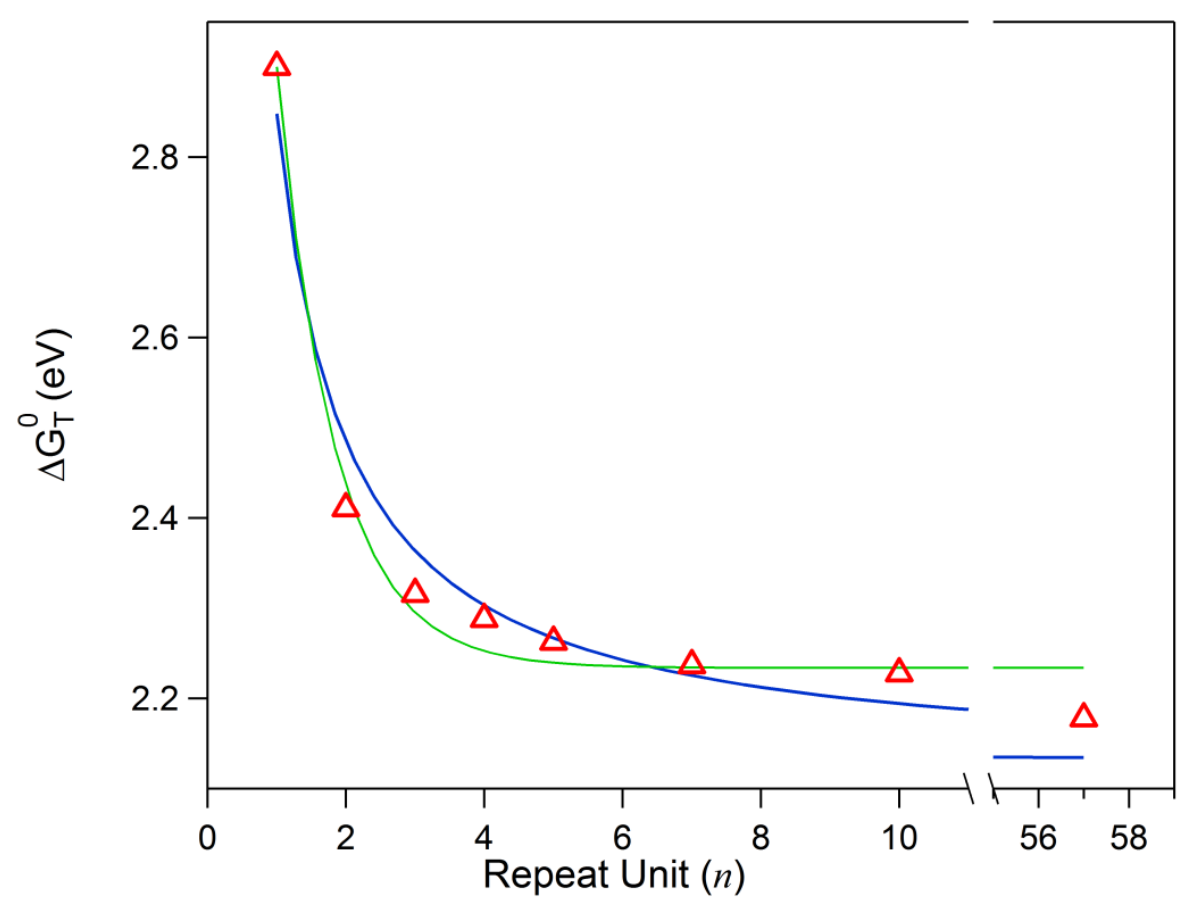


Figure S7: Dihedral Angles in the Lowest Triplet Excited State. Dihedral angles between adjacent fluorene repeat units in DFT optimized structures of the triplet ground states of the oligofluorenes $(n=3-7,10)$ are shown in (a). The dihedral angle closest to the center of the triplet is labeled as DA 0. Plots of the dependence of dihedral angles (DA) are shown in (b), with red lines mark the position of each dihedral angle. Values of DA 0 are $\phi \sim 1-10^{\circ}$, and those of DA \pm 1 and larger are $\phi \sim 28-33^{\circ}$. The dihedral angle differences between DA 0 and DA \pm 1 cause a 40-50 meV $\mathrm{m}^{4}$ energy barrier to the triplet exciton transport along the polyfluorene.

We see that in long oligomers three dihedral angles are perturbed from the $~ 36$ degrees typical of ground states. One, near the center of the triplet exciton is close to 0 degrees, while two others are around 30 degrees. These changes are consistent with the depiction in Figure $b$ in which the triplet exciton is approximately 3 units long, consistent with the conclusions from measurements of triplet free energies.
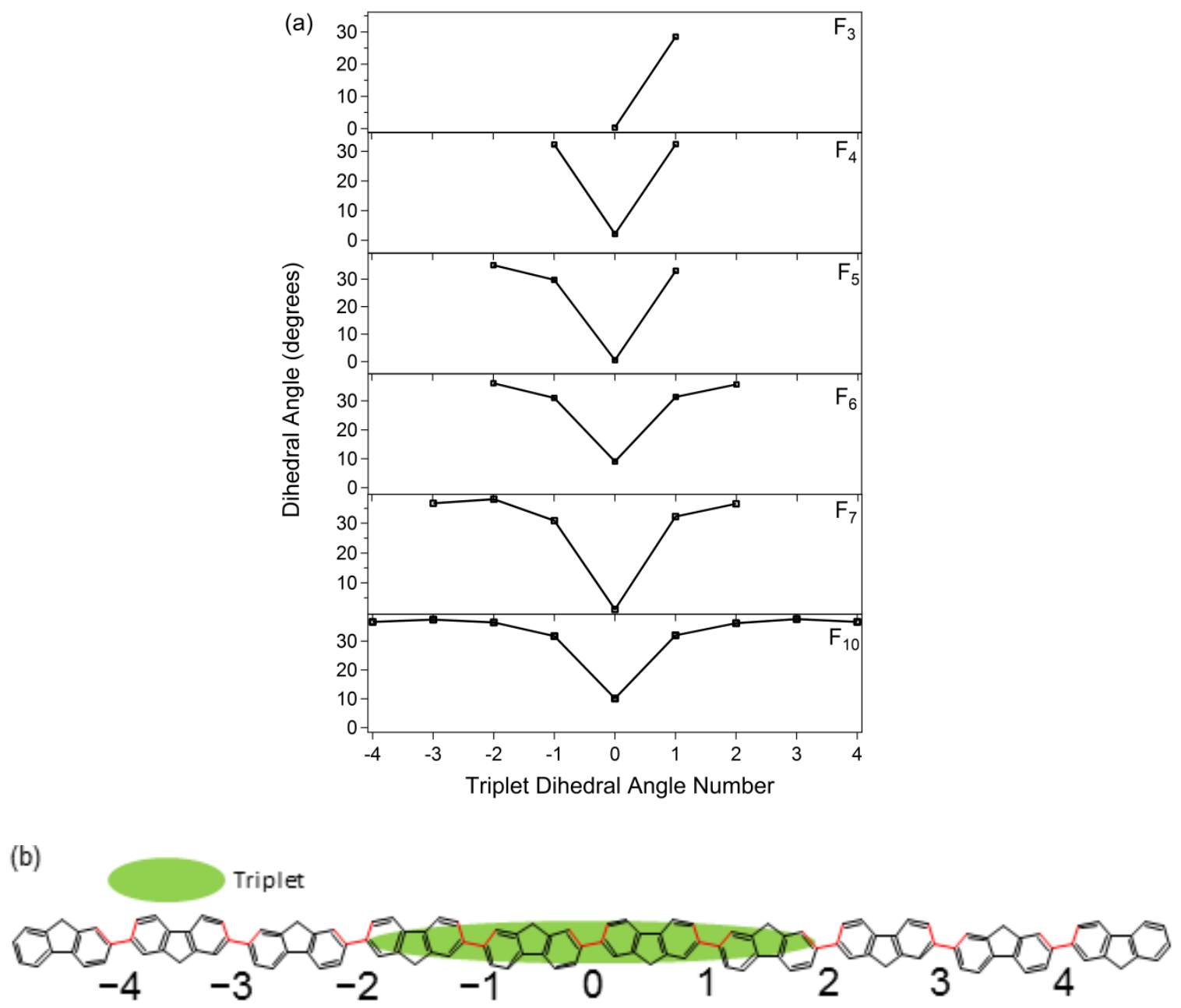


\section{References}

1. Martini, I. B.; Barthel, E. R.; Schwartz, B. J., Mechanisms of the Ultrafast Production and Recombination of Solvated Electrons in Weakly Polar Fluids: Comparison of Multiphoton Ionization and Detachment Via the Charge-Transfer-to-Solvent Transition of $\mathrm{Na}^{-}$in THF. Journal of Chemical Physics 2000, 113, 11245-11257.

2. Wasserberg, D.; Dudek, S. P.; Meskers, S. C. J.; Janssen, R. A. J., Comparison of the Chain Length Dependence of the Singlet- and Triplet-Excited States of Oligofluorenes. Chemical Physics Letters 2005, 411, 273-277.

3. Bredas, J. L.; Silbey, R.; Boudreaux, D. S.; Chance, R. R., Chain-Length Dependence of Electronic and Electrochemical Properties of Conjugated Systems: Polyacetylene, Polyphenylene, Polythiophene, and Polypyrrole. Journal of the American Chemical Society 1983, 105, 65556559.

4. Mani, T.; Miller, J. R., Role of Bad Dihedral Angles: Methylfluorenes Act as Energy Barriers for Excitons and Polarons of Oligofluorenes. The Journal of Physical Chemistry A 2014, 118, 9451-9459. 